\title{
LAS AUTORIDADES CIVILES DE NAVARRA ANTE EL DESORDEN PÚBLICO: CONTROL Y REPRESIÓN EN EL ANTIGUO RÉGIMEN
}

\author{
Javier Ruiz Astiz \\ Universidad de Navarra
}

\begin{abstract}
RESUMEN: La estabilidad social fue el principal anhelo de las autoridades civiles en la Navarra del Antiguo Régimen. Por ello para su consecución no dudaron en recurrir a distintas medidas encaminadas todas ellas a disciplinar las conductas nocivas de sus habitantes. Entre estas últimas nos encontramos con los desórdenes públicos, los cuáles trataron de ser controlados por sus nefastas consecuencias para el bienestar y sosiego comunitario. En su estrategia por lograr controlar y reprimir este tipo de comportamientos emplearon diferentes mecanismos que van a ser analizados en el presente artículo. Todo ello con el único objetivo de esclarecer cuál fue la actitud de las autoridades civiles en el reino de Navarra.
\end{abstract}

Palabras clave: Autoridades civiles, Control social, Represión, Violencia colectiva, Desórdenes públicos, Reino de Navarra, Edad Moderna.

ABSTRACT: The social stability was the main yearning of the civilian authorities in the Navarre of the Old Regime. For that reason for its attainment they did not doubt in resorting to different directed measures all of them to discipline the injurious conducts of its inhabitants. Between these last ones we were with the public disorders, who tried to be controlled by their ominous consequences for the communitarian well-being. In its strategy to manage to control and to repress this type of behaviours they used different mechanisms that are going to be analyzed in the present article. All this with the unique objective to clarify which was the attitude of the civilian authorities in the Kingdom of Navarre.

Keywords: Civilian authorities, Social control, Repression, Collective violence, Public disorders, Kingdom of Navarre, Early Modern Age. 


\section{Introducción}

La paz pública fue una aspiración habitual por parte de las autoridades civiles a lo largo de la Edad Moderna. Para lograr la estabilidad socio-comunitaria, éstas se adaptaron a las circunstancias existentes en cada momento y adoptaron distintas medidas para controlar todo tipo de algaradas, desórdenes y tumultos. Sin duda, la lucha contra este tipo de disturbios que alteraron el orden público se vio acrecentada a lo largo de los siglos modernos gracias a los importantes esfuerzos que pusieron en marcha las autoridades por lograr controlar y disciplinar a sus habitantes. Sin embargo, ¿tuvieron efectos los distintos mecanismos que fueron empleados?

Debemos entender que durante estos siglos las instituciones civiles Ilevaron a cabo distintas transformaciones culturales mientras intentaron imponer un adoctrinamiento de carácter paternal. A lo largo de estas centurias se dedicaron a conseguir la estabilidad social y política en cada localidad. Su propósito central fue mantener con firmeza el orden público, para lo que ejercieron un férreo control social. Fue entonces cuando comenzó, según Bernal Serna ${ }^{1}$ y Martínez Ruiz ${ }^{2}$, el proceso por el que el Estado intentó monopolizar el uso de la violencia para tratar de proteger a los individuos en sus respectivas comunidades. Como se comprobará las autoridades consiguieron importantes progresos en sus intenciones, aunque también es cierto que los oficiales de justicia no lograron imponerse, pese a que su papel resultó elemental para su control y para evitar que aumentase el número de excesos violentos. Por otro lado, como podremos apreciar la jurisprudencia trató de controlar las conmociones violentas que se originaron alterando e inquietando la quietud pública, aunque también se dedicó a reprimir con dureza los disturbios producidos para evitar que siguiesen reproduciéndose en otras circunstancias.

No obstante, para reconstruir este proceso represivo debo resaltar que las principales fuentes que he manejado han sido los procesos judiciales depositados tanto en el Archivo General de Navarra como en el Archivo Diocesano de Pamplona. Los objetivos de la presente investigación provocaron que realizase un análisis cualitativo de cada uno de ellos, por lo que he llevado a cabo un exhaustivo estudio de su contenido, profundizando con especial dedicación en las confesiones de cada testigo, en las declaraciones de los acusados, en las pruebas presentadas y en los argumentos dados por la defensa y el fiscal. Todo ello, para tratar de buscar indicios que ayuden a revelar los motivos que guiaron a las autoridades civiles a tratar de controlar estos acontecimientos.

1. Bernal Serna, L. M., Sociedad y violencia en Portugalete (1550-1833). Portugalete, 2007, p. 36 .

2. Martínez Ruiz, E., La seguridad pública en el Madrid de la Ilustración. Madrid, 1988, p. 19. 
No cabe duda que el análisis de la conflictividad cuenta con una fuente excepcional como son los procesos judiciales, los cuales poseen un extraordinario valor. Se trata de una verdadera mina para el conocimiento de los desórdenes públicos que sacudieron el reino de Navarra durante los siglos modernos, aunque también es cierto que cuentan con algunas deficiencias, puesto que a través de ellos no es posible llegar a conocer la conflictividad real sino únicamente la registrada, denunciada y juzgada. Aún con todo, estoy plenamente convencido de que gracias a este trabajo se logrará vislumbrar la actitud que manifestaron las autoridades navarras en la lucha contra los desórdenes públicos.

Al margen de las consideraciones sobre las fuentes empleadas para la elaboración de este artículo deseo resaltar que el espacio geográfico en el que he decidido enmarcar este estudio ha sido el reino de Navarra, aunque debo indicar que las intenciones que me planteo inicialmente son las de extrapolar situaciones concretas a lo que también sucedió en el resto de la Monarquía Hispánica, así como en todo el continente europeo. A la elección de esta temática han contribuido, a parte de una serie de motivos de naturaleza sentimental y afectiva, razones metodológicas de enorme relevancia. Estas últimas obedecen principalmente a la riqueza documental que poseen nuestros archivos, pues las fuentes con las que contamos son de una riqueza extraordinaria dada su cercanía y accesibilidad. Esto último se debe a la situación tan peculiar que disfrutó Navarra durante estos siglos, puesto que a pesar de la conquista castellana, el estatus de territorio incorporado a la Corona de Castilla le permitió conservar la práctica totalidad de las instituciones representativas del rey y del reino. Por tanto, considero que podemos reconstruir sin ningún tipo de problemas la sociedad europea del momento.

De este modo, y tras presentar los aspectos fundamentales que han contribuido a la elaboración de este estudio, creo conveniente indicar que en el presente artículo trataremos de analizar de un modo pormenorizado las distintas motivaciones que inspiraron la persecución de los disturbios que alteraron el orden público en las localidades navarras. Resaltando a su vez los diferentes mecanismos de los que se dotaron las instituciones civiles para tratar de reprimir estos excesos. No cabe ninguna duda de que esto último fue posible gracias al férreo control que ejercieron las autoridades respectivas a través de las rondas nocturnas, por un lado, y por otro a partir del recurso a los pleitos judiciales. Profundizar en ambos instrumentos de control y represión será otro de los objetivos que persiga este trabajo.

\section{2. ¿Por qué luchar contra el desorden público?}

Durante la Edad Moderna en el reino de Navarra se sucedieron los desórdenes públicos por toda su geografía. Entre los sucesos que las autoridades trataron de reprimir nos encontramos, en un primer grupo, los disturbios que fueron duramente perseguidos por sus comportamientos violentos. Este apartado com- 
prendería las pendencias, quimeras y multitud de enfrentamientos y alborotos. Aunque también es cierto que hubo situaciones en las que sin llegarse a una violencia física desatada sí que se produjeron alteraciones del orden público, como sucedió en numerosos motines y tumultos en los que sus protagonistas sabían perfectamente hasta donde podían llegar sin recurrir a actuaciones extremas. En segundo lugar, debemos destacar los excesos verbales que se cometieron, puesto que no sólo se centraron en sancionar las palabras injuriosas, los descomedimientos y los desacatos, sino también las proclamas difamatorias. Es decir, todos aquellos ataques que se centraron en la fama y el honor de las personas atacadas.

Sin duda, numerosas restricciones incidieron no sólo en las libertades individuales, sino que también trataron de controlar determinados comportamientos populares y festivos, y prohibir alborotos, motines y tumultos. Para ello las autoridades emitieron todo tipo de medidas para fiscalizar tanto el espacio en el que se producían los disturbios como el tiempo en el que se originaban. Junto a ello, las autoridades también se preocuparon de un modo particular en luchar contra aquellas proclamas difamatorias que atacaban a particulares e instituciones en detrimento, unas y otras, del orden público. Sin embargo, las motivaciones que existieron para luchar contra el desorden fueron muy diversas, aunque lo cierto es que no todas las disposiciones y medidas que se establecieron para intentar frenar dichos comportamientos fueron igual de eficaces. A continuación analizaré las causas que existieron para la represión de los acontecimientos que supusieron la alteración de la calma y el sosiego comunitario.

\subsection{Motivos para evitar que sucediesen desórdenes públicos}

Entre las causas elementales por las cuales las autoridades civiles desearon evitar la proliferación de desórdenes públicos debemos indicar su intención por lograr pacificar la sociedad navarra de los siglos modernos. Sin duda, la consecución de una perfecta cohesión vecinal, así como lograr el mantenimiento de la estabilidad política y social en cada comunidad justificó todas las acciones que emprendieron para poner fin a dichos excesos. Por todo ello, las autoridades locales desplegaron todo un arsenal de medidas de vigilancia y prevención contra los acontecimientos que podían perturbar la calma y el sosiego del vecindario ${ }^{3}$. Altercados en los que en numerosas ocasiones tuvieron que hacer

3. Véanse sobre esta cuestión los trabajos de Bazán Díaz, I., "La criminalización de la vida cotidiana. Articulación del orden público y del control social de las conductas", Imízcoz. La vida cotidiana en Vitoria en la Edad Moderna y Contemporánea. Donostia-San Sebastián 1995, p. 139; Iglesias Estepa, R., "Moral popular y tribunales de justicia en la Edad Moderna", Mantecón. Bajtín y la Historia de la Cultura Popular. Santander 2008, p. 319; Lorenzo Cadarso, P. L., "Ideas políticas y formas de protesta", Sesma Muñoz. Historia de la ciudad de Logroño. Zaragoza 1994, p. 296. 
frente, según Mantecón ${ }^{4}$, a toda una serie de intereses y rivalidades amparadas por la costumbre. Sin embargo, la adopción de dichas medidas de control y represión se vieron alentadas no sólo por la constante presencia de dichos sucesos violentos, sino a su vez porque las instituciones civiles asumieron la noción de orden público.

Sin duda, los alborotos populares supusieron una de las principales preocupaciones de las autoridades durante estas centurias. Resultó habitual que la furia del vecindario se manifestase a través del estallido de comportamientos reaccionarios en los que demandaban la satisfacción de sus exigencias. Lo que caracterizó a estos comportamientos fue su carácter colectivo. En lo que respecta al caso navarro podemos destacar los disturbios de cariz antiseñorial que se produjeron. Así, por ejemplo, en 1575 en la localidad de Dicastillo se produjo un alboroto contra Martín Ochoa, baile, cuando este personaje intentó apresar a Martín de Zalduendo, lo que provocó que varios vecinos fuesen en su ayuda contra Ochoa. Sin embargo, en este proceso el Fiscal recoge una interesante argumentación para el mantenimiento del orden público evitando los escándalos que se solían originar, ya que en este caso los acusados "delinquieron muy gravemente y quedaron todos muy escandalizados de haber visto un caso de tan grande atrevimiento y mal ejemplo de la república", lo que podía ocasionar "a no castigarse lo susodicho con mucho rigor y castigo ejemplar sería dar ánimo y atrevimiento a que los dichos lugares y vasallos del dicho Condestable se atrevan a hacer y cometer semejantes fuerzas y desacatos a vuestra justicia real y a los ministros de ella" ${ }^{\prime \prime}$.

Por otro lado, tampoco podemos obviar la causa criminal que se presentó en la localidad de Lerín en ese mismo año por parte del Fiscal y la villa contra Diego Ocio de Estrada y Alonso de Bargas porque trataron de sobornar a los vecinos para que les otorgasen un poder para lograr quitar la autoridad que detentaban el alcalde y los jurados en los pleitos que Ilevaban contra el Condestable de Navarra. Sin embargo, lo más destacado es que desde el punto de vista de la fiscalía estos personajes anduvieron "causando con ello el motín y alboroto" y dando "tantas y tan grandes ocasiones para que se amotinara y alborotara todo el lugar y hubiera muertes y sucedieran otros muchos escándalos y ruidos por lo cual conviene así para la buena administración de la justicia como para la pacificación, quietud y sosiego de aquella villa y ejemplo de la república que con particular rigor y demostración sean castigados" ${ }^{\prime 6}$.

También proliferaron con excesiva frecuencia los alborotos durante la celebración de reuniones concejiles. De este modo, cabe destacar el suceso que se

4. Mantecón Movellán, T. A., Conflictividad y disciplimaniento social en la Cantabria rural del Antiguo Régimen. Santander, 1997, p. 345.

5. AGN, Tribunales Reales. Procesos, núm. 69217, fol. 129.

6. AGN, Tribunales Reales. Procesos, núm. 28227, fol. 158. 
originó en 1610 en Artajona contra Jerónimo Lasterra, alcalde, con motivo de haber juntado el concejo para decidir sobre las deudas que algunos vecinos tenían contraídas con la parroquia local, lo que provocó que Pedro Lasterra, Antón Andía, Pascual Lascarro y otros compañeros se amotinaran irremediablemente. Sobre dichos sucesos el Fiscal nos informa que "vista la grande revuelta y cólera y alboroto de los susodichos y que de tal suerte fue esto contra el dicho alcalde y regimiento", pese a lo cual señalan que "no haber sucedido algún motín o escándalo" pues "lo temieron sucediese y que tienen por cierto hubiera sucedido si el dicho alcalde no procediera tan bien y templadamente como procedió" ${ }^{\prime \prime}$. Por tanto, no debe sorprendernos que en 1736 la localidad de Zuñiga se mostrase deseosa de conseguir que las juntas de concejo se celebrasen sin más inconvenientes ni excesos, logrando evitar de esta manera los constantes desórdenes públicos que en ellos se ocasionaban. Es por ello que pretendieron conseguirlo obligando a sus vecinos a que acudiesen a éstas "con el silencio, formalidad, modestia y atención que se debe tener en los actos de comunidad", favoreciendo y permitiendo a "los alcaldes, tenientes, regidores o personas a quien corresponda propongan y relacionen lo que en cada uno de dichos actos conviniere y después que así lo hayan ejecutado los vecinos que han ejercido dichos empleos de alcaldes y regidores, sean obligados a dar su razón según lo que cada uno comprendiese con la compostura y adorno correspondiente". Indican también que "oída la reconvención o razón que estos dieren hayan de seguir los que le sucedieren en su asiento, corriendo con esta formalidad hasta que concluyan todos los vecinos de razonar, para que mediante tan buena regla y economía se perciban todas las proposiciones que cada uno diere", todo ello como indican era necesario "para que se consiga la paz que se desea" ${ }^{\prime \prime}$.

Debo resaltar, a su vez, los desacatos que se ocasionaron contra las autoridades locales como uno de los desórdenes públicos que más se repitieron por toda la geografía navarra, los cuales fueron perseguidos para tratar de erradicar sus luctuosas consecuencias. Dichos altercados los encontramos en otros enclaves europeos en donde según Castán ${ }^{9}$ y Leguai ${ }^{10}$ fueron objeto de duras disposiciones para conseguir acabar con ellos. Entre los ejemplos que puedo reseñar cabe destacar el que tuvo lugar en 1581 en Tafalla, en donde se ocasionó un altercado en la iglesia fruto de la resistencia que Arnau Berges llevó a cabo con-

7. AGN, Tribunales Reales. Procesos, núm. 149820, fol. 6.

8. AGN, Tribunales Reales. Procesos, núm. 48619, fol. 9.

9. Castán, Y., "Mentalités rurale et urbaine à la fin de l'Ancien Régime Dans le ressort du Parlement de Toulouse d'après les sacs à procès criminels 1730-1790", Abbiateci. Crimes et criminalité en France 17e-18e siècles. Paris 1971, p. 159.

10. Leguai, A., "Les emotions et seditions populaires dans la generalite de Moulins aux XVIle et XVIIIle siecles". Revue d'histoire économique et sociale, 43 (1965), p. 64. 
tra algunos regidores de la localidad porque se había sentado en un lugar que correspondía a estos últimos. Pese a ello, lo más importante es apreciar cómo Juan de Abaurre, regidor, señaló que como consecuencia de aquella situación "luego se alborotó la gente y se levantaron de sus asientos"11. En otra ocasión se produjo un tumulto en 1659 en Villafranca debido a que Miguel de Zapata no quiso firmar una libranza que traía Martín García de Olloqui desde Tudela. Lo destacado es que, como recoge el Fiscal durante sus reflexiones, en dicho altercado "dieron causa y ocasión a suceder tan graves revueltas, daños y heridas que sucedieron y se juzgaron sucedieron mayores a no haberse puesto de por medio gente de buen celo y de tal suerte que ya la mayor parte de la gente se iba amotinando y sucedieron muchos desastres pues era mucho el tumulto". Desde su punto de vista era imprescindible que "en dicha ocasión habían de sosegar y apaciguar dicha pesadumbre como ministros de vuestra majestad" sin necesidad alguna de "haber pesadumbre en toda la dicha sala quien tuviese pesadumbre sino tan solamente el altercar sobre firmar una libranza"12. Por último, la falta de respeto que existió en muchas ocasiones contra las autoridades locales se aprecia también en el desorden público que estalló en 1785 en la ciudad de Pamplona, en el que tomaron parte dos militares Ilamados José Tapia y Manuel Ramírez. Lo importante de este suceso es que el fiscal, para evitar estos excesos, señala:

«No sólo están desaforados los militares que hicieren resistencia formal a las justicias ordinarias, sino también los que cometieren algún desacato contra ella de palabra u obra, quedando sujetos al conocimiento y castigo de las mismas, como recíprocamente, y en caso contrario lo deben estar los de otro fuero a los jueces militares, contra quienes ejecutaren desacato, o falta de respeto ${ }^{13}$.

Como se ha comprobado a lo largo de esta investigación, la noche fue el momento idóneo para que cuadrillas conformadas en su mayoría por los jóvenes solteros de cada localidad decidiesen salir a escandalizar al vecindario a través de su irreverente comportamiento. Las autoridades locales fueron conscientes en todo momento del peligro que suponían algunos acontecimientos para la estabilidad y el orden social de cada comunidad, puesto que dichas acciones se caracterizaban por numerosos rituales transgresores, prácticas difamatorias y elementos burlescos. Entre las actitudes que fueron duramente sancionadas cabe referirse a las siguientes: portar armas prohibidas, participar en rondas nocturnas, tocar instrumentos musicales, insultar y entonar serenatas en forma de matraca, así como salir disfrazados con máscaras y embozos de todo tipo.

11. AGN, Tribunales Reales. Procesos, núm. 119349, fol. 7.

12. AGN, Tribunales Reales. Procesos, núm. 123843, fol. 99.

13. AGN, Tribunales Reales. Procesos, núm. 156225, fol. 24. 
Sin duda, uno de los sucesos más frecuentes en este tipo de escarceos nocturnos lo constituyeron las cencerradas. A lo largo de los siglos modernos las autoridades locales trataron de reprimir este tipo de disturbios porque perturbaban la paz de sus habitantes ${ }^{14}$, por lo que fue habitual que promulgasen medidas represivas contra sus participantes. Así podemos destacar, por ejemplo, la matraca que tuvo lugar en Miranda de Arga en 1589 en la que tomaron parte Diego Bueno, Domingo Bueno, Jorge Bueno y Pascual Musgo. Sin embargo, lo importante para las autoridades fue evitar que volviesen a producirse este tipo de altercados, pues los condenados "son veceros en cometer semejantes delitos, son soberbios y que cada día andan en pendencias con unos y otros", todo lo cuál provocó que María Fidalgo viviese "con tanto peligro de su vida por causa de ellos" porque "son alborotados y se jactan de que lo han de matar", por lo que "conviene poner remedio en ello y se castiguen con rigor"15. Otro de estos sucesos se originó en 1594 en la localidad de Corella, en donde se produjo una cencerrada en la que participaron Domingo Virto y Pedro Vicente, quienes según señala el Fiscal "son personas de vida airada, amotinadores de la República y como tales de noches y horas cautas muchas y diversas veces han inquietado a los vecinos tratándoles de palabras feas e injuriosas y han causado grande escándalos". El objetivo de las autoridades, como se apreciará, fue evitar los escándalos que se ocasionaron porque estos personajes "de mucho tiempo a esta parte por ser como son deudos los unos de los otros han tomado costumbre de juntarse los unos con los otros de noches y a horas cautas, haciendo cuadrilla con espadas, broqueles y lanzas", quienes "por revolver el pueblo suelen echar mano a sus espadas y hacen grande ruido con ellas dando cuchilladas en puertas y en el suelo y de esta manera revuelven e inquietan a los vecinos de la dicha villa de Corella"16. Puede constatarse que una de las motivaciones que provocó que las autoridades tratasen de poner remedio a las perniciosas consecuencias que se derivaron de las prácticas chariváricas fue la perturbación del orden público, pues como señala el Fiscal que en 1596 acusó a Pedro de Orbaiz, Juan de Ansó, Guillén de Grez, Juan Remírez, Salvador Zurita y Martín de Rocaforte, vecinos de Sangüesa, estos personajes estuvieron una noche "ocasionando a voz en gritar a gentes que estaban quietas en sus casas, dijeron palabras deshonestas y escandalosas y ocasionadas para perturbar la quietud y sosiego de la villa"17.

14. Consúltense las investigaciones de Enríquez, J. C., Costumbres festivas y diversiones populares burlescas. Vizcaya, 1700-1833. Bilbao, 1996, p. 138; Bazán Díaz, I., "La criminalización de la vida...", p. 135; Martínez Gil, F.; Rodríguez González, A., "La fiesta en el mundo rural (siglos XVII-XVIII)", Martínez-Burgos; Rodríguez González. La fiesta en el mundo hispánico. Cuenca 2004, p. 312; Frijhoff, W., "Fête et loisir dans l'Europe du Nord-Ouest à l'époque moderne: contours d'une transition", Il tempo libero. Economia e società. Firenze 1994, p. 165.

15. AGN, Tribunales Reales. Procesos, núm. 213107, fol. 12.

16. AGN, Tribunales Reales. Procesos, núm. 12715, fol. 21.

17. AGN, Tribunales Reales. Procesos, núm. 99628, fol. 46. 
Aquellos actos estuvieron unidos no sólo al travestismo, sino que resultó frecuente que durante su transcurso se produjesen constantes denuncias en forma de gritos, burlas, serenatas, risas y abucheos contra sus destinatarios. Así sucedió, por ejemplo, en 1612 en la localidad de Arre, donde tuvo lugar una cencerrada en la que tomaron parte Martín de Echarri, Juan de Artica, Lope de Iribas, Juan de Iribas, Juan de Araiz, Juan de Sanchotena, Bernardo de Oricain, Juan de Labiano y Miguel de Zabalza. Lo cierto es que las autoridades consideraron que "los delitos que los dichos acusados han cometido son muy graves y dignos de pena corporal porque tienen fuerza de libelos infamatorios y se han de tener por tales, pues con tanta publicidad y a voces dijeron cosas tan perjudiciales" a través de las cuales pusieron "injusta nota en la lealtad de mujeres casadas, con ocasión que sucediesen muertes e inconvenientes y repararles y ha habido de esto muy grandes disensiones entre casados". Todo ello hizo que los acusados mereciesen un "castigo ejemplar en que escarmienten otros y más donde por las coplas que dijeron y cantaron a voces especificando las personas queda averiguado la grande malicia y deliberación y acuerdo con que procedieron los acusados"18.

Por otro lado, dentro de las conductas y los comportamientos que se vieron sometidos al control y represión por parte de las autoridades debo destacar las rondas nocturnas. Resultó frecuente encontrar en éstas a jóvenes, entre los que también se hallaron religiosos locales, deambulando por calles y plazas públicas mientras iban divirtiéndose al ritmo de la música, todo lo cual lo hicieron acompañados de distintas armas. Lo cierto es que las restricciones municipales contra el uso de armas fueron constantes en los siglos modernos con el único objetivo de evitar los graves altercados y enfrentamientos que de ello se podían originar con otros grupos o cuadrillas ${ }^{19}$. De este modo, no sorprende que una noche de agosto de 1714 en Corella se produjesen ciertos disturbios provocados por Bernabé García, Valero Virto, José Bardaxi, José Jiménez Bretón, Marcos de Luna, Domingo Virto, Pedro Jiménez, Miguel Delgado y Clemente Salcedo, quienes estuvieron lanzando piedras a las ventanas e inquietando y perturbando el sosiego del vecindario. Sin embargo, como indica el fiscal:

«Los acusados han cometido delitos gravísimos porque han andado inquietando a dicho barrio con sus guitarras y armados con espadas y broqueles, y a no atender mi parte a su estado y viendo semejantes excesos

18. AGN, Tribunales Reales. Procesos, núm. 41424, fol. 468.

19. Opinión que también comparten Bazán Díaz, I., "La criminalización de la vida...", p. 132; Brunet, M., Les pouvoirs au village. Aspects de la vie quotidienne dans le Roussillon du XVIIle siècle. Canet, 1998, p. 136; Candau Chacón, M. L., Los delitos y las penas en el mundo eclesiástico sevillano del XVIII. Sevilla, 1993, p. 125; Pitou, F., "Jeunesse et désordre social: les coureurs de nuit à Laval au XVIIle siècle". Revue d'Histoire Moderne et Contemporaine, 47-1 (2000), pp. 88-89. 
sino se hubiese contenido y saliese contra ellos podrían haber resultado gravísimos inconvenientes, siendo los dichos acusados los que dieron motivos a la mía y se contuvo» ${ }^{20}$.

En 1724 con motivo de las continuas rondas nocturnas que efectuaban los jóvenes solteros de Falces se produjo la muerte de Marcos Ochoa, presbítero, situación que motivó que el Fiscal apuntase que los disturbios que se generaban en este tipo de acontecimientos eran los que perturbaban la paz del vecindario, puesto que sus participantes iban por las calles "provocando a los vecinos y turbando la paz"21. Algo similar acaeció el 21 de septiembre de 1743 en la ciudad de Pamplona, en donde resultó herido Miguel de Cizur mientras iba en compañía de sus compañeros de cuadrilla. Durante las rondas nocturnas fue habitual que estallasen enfrentamientos en los que se originaron agresiones físicas y verbales. Debido a ello en este proceso judicial se recoge una cédula real promulgada durante el reinado de Felipe $V$ en la que se indica que desean "evitar las frecuentes muertes, riñas, insultos y otros escándalos que han acaecido de noche en esta ciudad con el pretexto de músicas y festejos con el deseo de la mayor quietud y sosiego" 22 . Es por ello que "considerando las continuas y repetidas pendencias y riñas, que algún tiempo a esta parte han sucedido y suceden de noche en esta ciudad resultando de ellas frecuentes muertes, heridas y otros escándalos sin que baste para evitar ni moderar las referidas desgracias la diligencia de los ministros de justicia que van de ronda, así de la jurisdicción ordinaria como de la militar turbándose por este medio la quietud pública y la seguridad de los que por previsión de sus ministerios han de andar de noche ${ }^{\prime \prime 23}$, por lo que:

"Ordenamos y mandamos a todos los vecinos, habitantes y moradores de esta dicha nuestra ciudad de cualquier calidad y condición, estado y dignidad que están, que desde la publicación de las presentes ninguno con el pretexto de música pueda salir de su casa de noche con armas o instrumentos de música para tañer con ellos como ni tampoco a oír la tal música ni acompañar a los que la dan, ni aguardar ni ofender a estos pena de que al que se encontrase o hallare con armas de fuego prohibidas, como son: pistoletes, carabinas, arcabuces pequeños, que por lo menos no tengan cuatro cuartas y media de cañón de la medida de este reino, o con armas blancas cortas como puñal o espada, que no sea de la ley se le impondrá y ejecutará la pena siendo noble o hijodalgo cuatro años de presidio cerrado de África y al presidio que no sea persona principal de cua-

20. AGN, Tribunales Reales. Procesos, núm. 205341, fol. 1.

21. AGN, Tribunales Reales. Procesos, núm. 126251, fol. 9.

22. AGN, Tribunales Reales. Procesos, núm. 6200, fol. 9.

23. AGN, Tribunales Reales. Procesos, núm. 6200, fol. 11. 
tro años de galeras al remo, y al que se hallase con armas que no sean prohibidas siendo noble o hijodalgo dos años de presidio cerrado de África y al presidio de dos años de galeras y la misma pena se le impone y se ejecutará respectivamente según su clase» ${ }^{24}$.

El 16 de junio de 1756 en Miranda de Arga ocasionaron un disturbio Juan Antonio de Udi y José de Torres, quienes según el Fiscal estuvieron "alborotando el pueblo contra lo dispuesto por auto acordado del vuestro Consejo y Bando publicado en su razón que prohíbe el que se salga de música de noches ni con armas bajo las penas que contiene ${ }^{\prime \prime 25}$. Lo mismo se indica en un proceso que tuvo lugar en Tafalla en 1762 con motivo de las rondas nocturnas que se sucedían noche tras noche en esta localidad, debido a lo que se recoge una Real Orden promulgada durante el reinado de Fernando VI en la que se hace referencia a "las muertes, robos, pendencias y otros graves desórdenes que se cometían en esta ciudad en músicas y festejos", todo lo cual eran "pretextos de que se valía la juventud para andar de noche por las calles a fin de lograr sus injustos disimulados intentos". Por todo ello se establecieron las siguientes medidas para evitar estos sucesos:

«Mando que ninguna persona con el pretexto de música pueda salir de noche de su casa con armas ni instrumento músico ni acompañando a los que la dan ni guardar ni defender a estos, pena de que al que se encontrare o hallare con armas de fuego prohibidas como son pistoletes, carabinas, arcabuces pequeños que por lo menos no tengan cuatro cuartas y media de cañón de la medida de este reino con armas blancas cortas como puñal o espadas que no sea de medida de la ley se le imponga y ejecute la pena siendo noble o hijodalgo de cuatro años de presidio cerrado de África y al servicio de cuatro años de galeras al remo y al que se hallare con armas que no sean prohibidas siendo noble o hijodalgo dos años de presidio cerrado de África y al servicio dos años de galeras y la misma pena se impuso respectivamente según su clase al que se hallare o encontrase con algunos instrumentos de música aunque no lleve armas ofensivas ni defensivas y al que se hallare que sale con solo el fin de oír la música y acompañar a los que la dan aunque no lleve armas ni instrumentos algunos se le impuso también dos años de destierro preciso de este reino ejecutándose estas penas aunque no se prenda a los contraventores en el acto $»^{26}$.

El fiscal acusó en 1768 a Joaquín Lorenz, Antonio Pérez, Antonio Goñi, Antonio de Oroz y Diego Andueza, vecinos de Mendigorria, quienes contravinieron "las provisiones publicadas en todo el reino que prohíben en dar músi-

24. AGN, Tribunales Reales. Procesos, núm. 6200, fol. 13.

25. AGN, Tribunales Reales. Procesos, núm. 21294, fol. 47.

26. AGN, Tribunales Reales. Procesos, núm. 127540, fol. 17. 
cas por las noches y uso de armas con el justísimo fin de evitar los gravísimos desórdenes que se habían experimentado", pese a lo que salieron la noche del 17 de septiembre con armas e instrumentos musicales "alborotando el sosiego y quietud pública", habiendo incurrido de esta manera "en las penas que prescriben dichas provisiones y reales bandos" ${ }^{27}$. Lo mismo sucedió en 1771 en Fustiñana, donde se produjo una ronda nocturna en la que tomaron parte activa Miguel Ferrer, Roque de Salvatierra y Ramón Gil, siendo éste un acto en el que según las autoridades estos personajes solían ir "gritando y cantando a su antojo sin dejar descansar al vecindario" ${ }^{\prime 28}$. Tampoco debe sorprender que en 1776 en la localidad de Milagro saliesen de ronda distintos jóvenes, entre los que se encontraron Francisco Antonio de Echarri y Juan de Arcos, quienes como remarca el Fiscal salieron "por las calles de la villa alborotando la quietud pública y dando música con una guitarra o vihuela causando en esta república el escándalo que se deja conocer ${ }^{\prime \prime 2}$. Parece ser que en 1800 en la localidad de Cascante las rondas nocturnas se habían convertido en una pauta constante y frecuente de las cuadrillas de jóvenes, puesto que el Fiscal señalaba que resulta inaguantable "el extremo a que llegó el abuso y desorden de la juventud", la cual se dedicaba a perturbar "por las noches la pública quietud y tranquilidad del vecindario con músicas, disparo de armas de fuego y piedras a las casas". Debido a ello, ¿cuál fue la actitud de las autoridades? El objetivo primordial de éstas fue lograr "evitar que se implicasen en otros excesos a que estaban tan viciados", para lo que exigieron "que se proceda al castigo con el mayor rigor y seguridad que prescriben las leyes a fin de reprimir la osadía y mantener el buen orden del numeroso vecindario de este pueblo" ${ }^{\prime \prime 30}$. Sucesos similares son los que sucedieron en Allo en 1806, en donde Manuel Osaba, Pedro Laspeñas, Isidoro Azcona, Pablo Osaba, Matías Alegría y Pedro Agustín Alonso fueron denunciados por el Fiscal por su participación en algunos excesos nocturnos, ya que según señala la parte demandante "se cometen por los mozos de ella los mayores atentados las más de las noches insultando dentro de las mismas casas a muchas personas, robándoles cuanto les sugiere su mala inclinación y alborotando después todo el pueblo" ${ }^{\prime 31}$.

Junto a las rondas nocturnas y las consecuencias que de ellas se podían originar, cabe referirse también a las pendencias y quimeras que se originaron en las tabernas. Debemos ser conscientes de que la embriaguez fue la causante de numerosos disturbios comunitarios. Los altercados que surgieron en torno a estos emplazamientos también fueron duramente criticados por las autoridades

27. AGN, Tribunales Reales. Procesos, núm. 127582, fol. 7.

28. AGN, Tribunales Reales. Procesos, núm. 22011, fol. 88.

29. AGN, Tribunales Reales. Procesos, núm. 127919, fol. 15.

30. AGN, Tribunales Reales. Procesos, núm. 194036, fol. 141.

31. AGN, Tribunales Reales. Procesos, núm. 141576, fol. 103. 
civiles y eclesiásticas, por lo que el objetivo de éstas fue prevenir y evitar que se produjesen dichos sucesos. Así, por ejemplo, en 1563 el concejo de Aquerreta presentó una demanda contra los taberneros de la localidad porque según ellos "hay en el dicho lugar dos tabernas públicas de vender vino" a donde "todos los vecinos y habitantes del dicho lugar han ido y van cada día a jugar a las dichas tabernas y se recogen en ellas de día y de noche gastando sus bienes y haciendas y también han sucedido muertes y heridas y escándalos en las dichas tabernas". Junto a ello señalan que "no hay necesidad en el dicho pueblo de las dichas tabernas por no ser el dicho lugar pasajero ni paso de viandantes y por ello no conviene en ninguna manera que haya tabernas algunas públicas", por lo que "suplican a vuestra majestad conforme al poder que presentan con esta petición mande por una provisión e inhibición penal que de aquí adelante no hayan de tener ni tengan tabernas algunas públicas de vinos en el dicho lugar" ${ }^{\prime 2}$. Un suceso similar tuvo lugar en 1754 en la ciudad de EsteIla, en donde las autoridades trataron de poner remedio a los disturbios que se originaban en las tabernas durante las noches, por lo que deseaban controlar su horario de apertura, para lo que presentaron una cédula promulgada por Fernando VII en la que se hacía referencia a "las muertes, robos, pendencias, insultos y otros graves desórdenes que se cometían en esta ciudad, en músicas, y festejos, pretextos de que se valía la juventud para andar de noche por las calles a fin de lograr sus injustos y disimulados intentos". Por todo ello pretenden que "ninguna persona con el pretexto de música pueda salir de noche de su casa con armas, ni instrumento músico, ni acompañar a los que la dan, ni guardar, ni defender a éstos, pena de que al que se encontrare o hallare con armas de fuego prohibidas, como son pistoletes, carabinas, arcabuces pequeños, que por lo menos no tengan cuatro cuartas y media de cañón, de la medida de este reino, o con armas blancas cortas, como puñal, güífero o espada, que no sea de la medida de la ley, se le imponga y ejecute la pena, siendo noble o hijodalgo, de cuatro años de presidio cerrado de África, y al plebeyo de cuatro años de galeras al remo, y al que se hallare con armas que no sean prohibidas, siendo noble o hijodalgo, dos años de presidio cerrado de África, y al plebeyo, dos años de galeras, y la misma pena se impuso respectivamente, según su clase, al que se hallare o encontrare con algunos instrumentos de música, aunque no lleve armas ofensivas ni defensivas, y al que se hallare que sale con solo el fin de oír la música y acompañar a los que la dan, aunque no lleve armas ni instrumentos algunos, se le impuso también la de dos años de destierro preciso de este reino" ${ }^{\prime 3}$. También se indica "que ninguno afianzado en las esquinas, calles o plazas, ni llevar monteras con alas caídas, pena de cien libras aplicadas la mitad para vuestra cámara y fisco", así como "que ninguno pueda con algún

32. AGN, Tribunales Reales. Procesos, núm. 66966, fol. 1.

33. AGN, Tribunales Reales. Procesos, núm. 92954, fol. 4. 
pretexto, aunque sea de defensa, tirar piedras, pena de que al que se le comprobare se le impondrá, siendo de la edad de catorce años abajo, la de cien libras, aplicadas en la misma forma, y siendo de los catorce años hasta veinte, cuatro años de destierro de este reino, y siendo de los veinte años de edad arriba, cuatro años de presidio cerrado de África, o de servicio a vuestra real persona, y que en todos los referidos casos, indistintamente se les exijan cien libras". Como consecuencia de todo ello lo que las autoridades locales desean es que "todas las tabernas se cierren a las oraciones, $y$ a los que se encontraren bebiendo en ellas, pasada dicha hora, se les impongan las penas, que pareciere a vuestro Consejo, como asimismo a los dueños, que las tuvieran abiertas" ${ }^{\prime \prime 3}$.

A su vez, también debo indicar los desórdenes públicos que se originaron en momentos festivos, los cuales fueron duramente perseguidos por las autoridades en forma de disposiciones y medidas legales para la vigilancia del orden público. Estas últimas trataron de evitar las concentraciones de personas y los sucesos que de ellas se podían derivar. A través de estos mecanismos el Estado intentó a su vez instrumentalizar dichas manifestaciones populares, aunque lo cierto es que no lograron poner fin a estas celebraciones. Sin duda, uno de los festejos que se mostraron más proclives a ocasionar altercados violentos fueron los carnavales. El continente europeo se vio salpicado de disturbios durante estas jornadas, lo que provocó -como señalan Muir ${ }^{35}$ y Gaignebet ${ }^{36}$ - que proliferasen los decretos emanados por parte de las instituciones civiles. En el caso navarro los excesos que se cometieron también fueron frecuentes. De este modo, en 1553 el fiscal y la localidad de Larraga demandaron a Antón de Mateo y Jorge Ibáñez por salir durante las jornadas carnavalescas con armas prohibidas por sus calles de noche. Lo cierto es que estos comportamientos eran habituales en dichos festejos, puesto que los demandantes aseguran "que las noches de carnestolendas acostumbra el regimiento local de tiempo inmemorial hasta ahora a hacer vedamiento que ninguno salga de noches por las calles de la dicha villa con armas so pena de perderlas" haciendo "pregonar ese vedamiento por las calles de la dicha villa para que venga a noticia de todos los dichos jurados para ejecución de los pregones acostumbran rondar la dicha villa". Pero lo más importante es que esto lo hacen "para evitar que no suceda algún escándalo", por ello "prenden a los escandalosos y disponen las penas en que incurren ${ }^{\prime \prime 37}$. Un suceso parecido tuvo lugar en 1560 en la ciudad de Pamplona, en donde el Fiscal presentó un proceso judicial contra Miguel de Laobra por los excesos que se cometieron durante dichas jornadas, sin embargo, lo más

34. AGN, Tribunales Reales. Procesos, núm. 92954, fol. 5.

35. Muir, E., Ritual in Early Modern Europe. London, 1997, p. 104.

36. Gaignebet, C., "Le combat de Carnaval et de Carême de P. Bruegel (1559)". Annales. Économies, Sociétés, Civilisations, 2 (1979), p. 332.

37. AGN, Tribunales Reales. Procesos, núm. 86328, fol. 3. 
destacado es que según la demanda el acusado "otras muchas noches y veces ha hecho lo mismo y suele andar y anda a solas y en cuadrillas por esta ciudad de noches dando causa y ocasión a cuestiones, heridas, muertes y otros muchos males $^{\prime 38}$. Por otro lado, en 1636 en la localidad de Ablitas distintos vecinos nos relatan los motivos que las autoridades tenían para luchar contra los excesos que se cometían durante los carnavales. De este modo, Juan de Macayo señala que el 2 de febrero "se echó un pregón en la dicha villa el domingo de carnestolendas diciendo que ninguna persona fuese osada a dar matracas ni tirar ollazos de ceniza poniendo penas al que lo contraviniese", cosa que "ha sido todos los años continuamente ${ }^{\prime \prime 39}$. Postura similar es la que muestra Sebastián de Aguirre, quien indica que "habrá dieciocho o diecinueve años que comenzaron a pregonar los domingos de carnestolendas bandos prohibiendo dar matracas y demás sucesos que pudiesen acaecer ${ }^{\prime \prime 4}$.

Junto a las celebraciones carnavalescas existieron otro tipo de fiestas locales que también fueron perseguidas por las autoridades con el único fin de controlar los acontecimientos violentos que se derivaron de ellas. La defensa del orden público constituyó su principal preocupación, ya que estos festejos supusieron una interrupción pasajera del sosiego y la calma que se veían sumidas en la diversión y el jolgorio. Dentro de las festividades que podían desencadenar trágicas consecuencias en forma de altercados comunitarios podemos destacar las distintas procesiones que se celebraron a lo largo del año. Martínez $\mathrm{Gil}^{41}$ nos informa detalladamente para el caso manchego sobre las nefastas situaciones que se derivaron de aquéllas. En lo que a Navarra hace referencia debo incidir en el proceso judicial que en 1582 inició el Fiscal en la ciudad de Tudela porque allí "se acostumbra todas las pascuas de resurrección de nuestro señor Jesucristo hacer en las parroquias ciertas procesiones a ermitas extramuros de la dicha ciudad en las cuales con muy grande abuso en grande deservicio de dios nuestro señor acostumbran ir compañías de soldados que para ello inventan armados con arcabuces, picas y otras armas Ilevando bandera tendidas y a tambores en lo cual demás que pervierten a los clérigos y a otras personas que van con devoción en las dichas procesiones, son causa y ocasión de que sucedan escándalos y vías de hecho como realmente han sucedido". De este modo, el 22 de abril de ese año se ocasionó un nuevo altercado en donde gracias a la intervención del alcalde y de otras gentes no sucedieron "muertes y otros daños", aunque señala que "sucederán de aquí adelante sino se prohíbe el tal abuso so recias penas, mandando a los procuradores primicieros y parroquia-

38. AGN, Tribunales Reales. Procesos, núm. 10346, fol. 15.

39. AGN, Tribunales Reales. Procesos, núm. 202227, fol. 44.

40. AGN, Tribunales Reales. Procesos, núm. 202227, fol. 48.

41. Martínez Gil, F.; Rodríguez González, A., "Estabilidad y conflicto en la fiesta del Corpus Christi", Fernández; Martínez. La fiesta del Corpus Christi. Cuenca 2002, p. 43. 
nos de las tales parroquias y a todos los demás que fuere necesario que de hoy más no salgan en las dichas procesiones soldados ni gente a punto de guerra para que se eviten y remedien semejantes escándalos" ${ }^{\prime 42}$.

Sin embargo, las críticas y quejas lanzadas contra las fiestas patronales fueron mucho más virulentas durante estos siglos, pues resultó habitual que sus participantes terminasen dichas jornadas en continuas riñas y peleas. Del Río ${ }^{43}$, Amigo Vázquez ${ }^{44}$ y Pellegrín ${ }^{45}$ dan buena muestra de los ataques de los que fueron objeto. Así, por ejemplo, en 1602 el municipio de Uterga presentó una demanda contra varios vecinos, entre los que se encontraron Gregorio de Aniz, Pedro de Esparza y Pedro de Gazólaz, con motivo de los excesos que se cometían durante las fiestas de la localidad, puesto que en ellas "sucedían riñas, muertes y escándalos", por ello los jurados locales "por evitarlos acudieron a la Real Corte y pidieron en ellas se remediasen estos inconvenientes" ${ }^{\prime \prime 6}$. Por último, tampoco las corridas de toros que se organizaron en muchas localidades navarras se libraron de experimentar disturbios vecinales. No sorprenderá, por tanto, que en junio de 1592 el sustituto fiscal de Tudela se quejase de los altercados que se solían originar durante las jornadas festivas en torno a las corridas de toros. Así denuncia que Jerónimo López, Miguel López, Domingo de Haya, Juan de Salazar y Alonso Pablo, vecinos de Cascante, estuvieron "en cuadrilla y camarada", con lo que "revolvieron y amotinaron la gente que estaba en las dichas fiestas de tal manera que causaron motín público de pueblos, y que sucedieran muertes y heridas y otros notables daños". Ante esta situación tuvieron que ir las autoridades locales "apellidando la voz del rey a poner paz y quietud sobre la gente y evitar los dichos daños" ${ }^{\prime \prime 7}$.

Como se ha podido comprobar a lo largo de estas líneas, las autoridades civiles trataron de hacerse con el monopolio de la violencia a través del control de los resortes del aparato judicial y gubernamental con el objetivo primordial de pacificar la sociedad navarra de los siglos modernos. Lo mismo sucedió en otros territorios del continente europeo según lo atestiguan los estudios de algunos investigadores ${ }^{48}$. Todo ello como consecuencia de las nefastas consecuen-

42. AGN, Tribunales Reales. Procesos, núm. 88101, fol. 1.

43. Del Río, M. J., "Francisco Santos y su mundo: fiesta popular y política en el Madrid barroco", Mantecón. Bajtín y la Historia de la Cultura Popular. Santander 2008, p. 178.

44. Amigo Vázquez, L., "Fiestas de toros en el Valladolid del XVII. Un teatro del honor para las élites de poder urbanas". Studia Histórica, 26 (2004), p. 310.

45. Pellegrín, N., Les bachelleries. Organisations et fêtes de la jeunesse dans le CentreOuest, XVe-XVIIle siècles. Poitiers, 1983, p. 276.

46. AGN, Tribunales Reales. Procesos, núm. 120967, fol. 1.

47. AGN, Tribunales Reales. Procesos, núm. 39799, fol. 2.

48. Merece la pena consultar los trabajos efectuados por Collins, J. B., La Bretagne Dans l'État royal. Classes sociales, États provinciaux et ordre public de l'Édit d'Únion à la révolte des Bonnets rouges. France, 2006, p. 276; Lorenzo Cadarso, P. L., "El recurso a la violencia política en el Antiguo Régimen: la violencia colectiva popular", Munita. Conflicto, violencia y cri- 
cias que conllevaron para el bienestar social y político de cada comunidad los desórdenes públicos que se originaron con relativa frecuencia.

\section{2. ¿Por qué controlar la publicación de libelos y pasquines?}

Libelos y pasquines desempeñaron un papel protagonista en algaradas y desórdenes públicos. En definitiva, surgieron ante cualquier situación de malestar que apareciese entre los miembros de una misma comunidad. Colocar o distribuir escritos difamatorios se convirtió en uno de los métodos más extendidos durante la Edad Moderna. Sin duda, resultaron eficaces, por lo que uno de sus aspectos más relevantes fue que éstos debían de ser coetáneos a los hechos a los que hacían mención, aunque también hubo ocasiones en que versaron sobre sucesos anteriores que habrían pervivido en el imaginario de la comunidad. Pese a esto último, la colocación de cualquier proclama difamatoria vino dada por la cercanía a los acontecimientos a los que se referían. Lo cierto es que en cada caso existieron ciertos detonantes o desencadenantes que propiciaron la aparición de este tipo de soportes. En la mayoría de las ocasiones no se trató de una elección casual, sino que las circunstancias marcaron el momento en el que se podía propiciar un mayor revuelo. No debemos olvidar que estas manifestaciones, a parte de lanzar sus pullas contra ciertas personalidades, pretendieron atraer para sí al expectante público que permanecía a la espera de nuevas proclamas. Es por ello por lo que no resulta descabellado pensar que alborotos y algaradas se vieron alentados por este tipo de herramientas publicitarias. Por lo tanto, es normal que promoviesen -como señalan $\operatorname{Thompson}^{49}$ y Margerison ${ }^{50}$ - ciertas actuaciones o que estimulasen en sus receptores un sentimiento reaccionario.

Muchos autores han incidido en que una de las principales características de todos los conflictos sociales y políticos que tuvieron lugar a lo largo de los siglos modernos fueron las distintas manifestaciones de violencia que aparecieron, tanto escritas como verbales. Lo cierto es que la naturaleza de estos acontecimientos se percibe de un modo más comprensible a partir de sus palabras en vez de por sus actos. Por tanto, lo que caracterizó a muchos de estos sucesos fue la enorme variedad de proclamas que surgieron en torno a ellos. De esta manera, libelos y pasquines pueden ser concebidos -como señala Castillo

minalidad en Europa y América. Vitoria-Gasteiz 2004, p. 176; Mantecón Movellán, T. A., “Desviación, disciplina social e intervenciones judiciales en el Antiguo Régimen". Studia Histórica, 14 (1996), p. 239; Ruff, J., "Popular violence and its prosecution in seventeenth-and eighteenthcentury France", Mc Mahon. Crime, Law and Popular Culture in Europe, 1500-1900. London 2008, p. 40.

49. Thompson, E. P., Costumbres en común. Barcelona, 2000, p. 538.

50. Margerison, K., Pamphlets and Public Opinion. The campaign for a Union of Orders in the Early French Revolution. Indiana, 1997, p. 37. 
Gómez ${ }^{51}$ - como termómetros capaces de medir las inquietudes y agitaciones sociales que tuvieron lugar. Durante el desarrollo de cualquier acción de naturaleza colectiva su presencia resultó decisiva. Al menos esto es lo que opinaba el Fiscal Ovando cuando analizaba los sucesos que habían tenido lugar en Corella en 1561. Parece ser que se publicaron una serie de coplas a manera de libelo difamatorio en las que se lanzaron durísimas acusaciones y difamaciones contra los cristianos nuevos. Según éste, aquellos cantares injuriosos se reprodujeron "diversas veces de noche y de día, dando causa y ocasionando enojos, cuestiones y revueltas", a lo que más adelante añadió que:

«Por las calles públicas de las casas de esta dicha villa algunos mancebos han cantado públicamente y a altas voces ciertas coplas en mucho agravio y perjuicio de los vecinos de la dicha villa. Y si a ello se diese lugar se podría suceder y haber muchos escándalos, muertes y cuestiones» ${ }^{52}$.

No importa de qué tipo de desorden estemos hablando porque lo realmente interesante es que libelos y pasquines lograron florecer en circunstancias muy diversas. Su presencia puede rastrearse en multitud de disturbios socio-comunitarios. De este modo, por ejemplo, en muchos casos de carestía o falta de subsistencias fue frecuente que apareciesen escritos de carácter difamatorio en contra de la situación tan negativa en la que se encontraban. Queda claro, por tanto, que junto a los desórdenes que se experimentaron durante las crisis de carácter alimenticio aparecieron de forma conjunta libelos y pasquines. Ambos actuaron como un vehículo imprescindible para canalizar todo tipo de amenazas en las que, según $\mathrm{Croft}^{53}$, subyacía el recurso a la violencia si los agravios demandados no lograban ser remediados. Si bien se ha comprobado como uno de los fenómenos que dio lugar a la publicación de una ingente cantidad de proclamas fue la falta de bastimentos, sin embargo, no sólo surgieron manifestaciones de esta naturaleza en este tipo de conflictos, sino también ante cualquier tipo de disposición que resultase perjudicial. Por ello, la negativa ante ciertas medidas o condiciones se manifestó, en muchas ocasiones, a partir de la publicación de toda una serie de escritos que atacaron o se mostraron contrarios a su aplicación.

Es necesario recalcar que gracias a estos mecanismos de expresión podremos reconstruir el clima de inestabilidad que caracterizó a muchos de estos acontecimientos. No debemos olvidar tampoco el importante papel que desempeñaron durante las cencerradas practicadas por la comunidad. Durante su desarrollo fue usual encontrarse escritos injuriosos o coplillas denigrativas.

51. Castillo Gómez, A., Escribir y leer en el siglo de Cervantes. Barcelona, 1999, p. 149.

52. AGN, Tribunales Reales. Procesos, núm. 145456, fol. 1.

53. Croft, P., "Libels, Popular Literacy and Public Opinion in Early Modern England". Historical Research, 68 (1995), p. 270. 
Prácticas que se convirtieron en parte esencial de la reprobación colectiva que se ejerció a través de estas actuaciones ${ }^{54}$. Es por todo esto por lo que como puede comprobarse, durante el devenir de cualquier tipo de conflicto surgieron libelos y pasquines. Desde mi punto de vista, unos y otros pueden ser considerados como elementos inseparables. Se podría decir, tal y como apuntó Darnton $^{55}$, que supieron explotar todas las grandes crisis habidas a lo largo de la historia. Sin embargo, lo más destacado fue que por muy pequeño o reducido que fuese un conflicto, ello no quiso decir que no recurriesen a ellos. A nivel comunitario hubo un elevado número de micro-conflictos, en los cuáles estuvieron presentes de forma habitual.

Sin embargo, aparte de su manifiesta relación con los desórdenes públicos, ¿qué provocó el interés de las autoridades por tratar de controlar la aparición de estas manifestaciones escritas? Hay que tener en cuenta que libelos y pasquines ofrecieron las fórmulas incitantes de una nueva verdad. Surgieron con unos determinados objetivos, entre los cuales se encontró informar e injuriar, aunque todos ellos podríamos reducirlos a que procuraron influir en sus receptores. Es por ello por lo que para conseguir una mayor repercusión buscaron espacios concurridos en donde podían ser percibidos por un público mucho mayor. Cabe preguntarse por tanto, ¿influyeron éstos en la conformación de estados de opinión?

Como he indicado anteriormente, se trató de manifestaciones que surgieron en determinados momentos, sin embargo su común denominador fue que necesitaron de un número relevante de espectadores para lograr que su eficacia fuese la mejor posible. Su única finalidad, como indicó Egido López ${ }^{56}$, fue la de ganar adeptos, para lo que en muchas ocasiones tuvieron que recurrir a unas fórmulas mucho más básicas y sencillas con lo que lograr cautivar a un auditorio de mayor envergadura. Debemos ser conscientes de que estamos hablando de un público que en su gran mayoría estuvo conformado por personas analfabetas, que no supieron leer y mucho menos escribir. No obstante, entre los siglos XVI y XVIII los índices de alfabetización fueron en claro aumento, pese a

54. Aspecto que también es reseñado en los trabajos de Castan, N., "Contentieux social et utilisation variable du charivari à la fin de l'Ancien Régime en Languedoc", Le Goff; Schmitt. Le Charivari, París 1981, p. 199; Enríquez, J. C., Costumbres festivas..., p. 102; Ingram, M., "Ridings, rough music and mocking rhymes in Early Modern England", Read. Popular culture in Seventeenth-Century England. London 1981, p. 252; Muir, E., Ritual in Early..., p. 102; Schindler, N., Rebellion, Community and Custom in Early Modern Germany. Great Britain, 2002, p. 152; Usunáriz, J. M., "El lenguaje de la cencerrada: burla, violencia y control de la comunidad", García Bourrellier; Usunariz. Aportaciones a la Historia Social del Lenguaje: España siglos XIV-XVIII. Madrid 2006, pp. 247-248.

55. Darnton, R., "The high enlightenment and the low-life of literature in pre-revolutionary France". Past and Present, 51 (1971), p. 105.

56. Egido López, T., Opinión pública y oposición al poder en la España del siglo XVIII (1713-1759). Valladolid, 2002, p. 51. 
que no se produjo de un modo homogéneo, sino que se pueden apreciar -como indican García de Enterría ${ }^{57}$ y Galende Díaz ${ }^{58}$ - ciertas desigualdades en razón del lugar, el sexo y de la actividad profesional. Teniendo en cuenta estos factores, ¿cómo hablar de la influencia de libelos y pasquines en las esferas de opinión comunitarias?

Sin duda alguna, el grueso de la sociedad fue la destinataria de dichas proclamas, dentro de los cuales hubo un enorme porcentaje de personas que desconocieron la lectura, por tanto, ¿cómo lograron acceder a esas manifestaciones escritas? Estoy convencido de que lo hicieron de forma hablada o cantada. Gracias a la comunicación oral lograron acercarse a las nuevas proclamas difamatorias que aparecían en cada comunidad, pues cabe recordar que la lectura directa y personal durante la Edad Moderna fue un privilegio de unos pocos. Por ello, como señala Bouza ${ }^{59}$, la voz puede considerarse como un remedio destinado a paliar el analfabetismo imperante en aquellos siglos. La recepción de dichos textos estuvo apoyada en su divulgación oral, bien fuesen leídos o comentados en voz alta. Se trató, entonces, de un público que puede ser calificado como ocasional. Muchas veces si no pudieron ser receptores de primera mano lo fueron de un modo indirecto. El cotilleo y el chismorreo se convirtieron en herramientas básicas de esta literatura subversiva. A través de ellos se logró alcanzar a un número de espectadores mucho mayor y gracias a estas prácticas fue como muchos se enteraron de ciertos asuntos.

Libelos y pasquines fueron arrojados en calles, plazas y mercados, o bien fijados en lugares de paso o en cualquier edificio, a la vez que fueron entregados en mano o cantados. Resulta probable, de este modo, que los textos que se hallaron fuesen recitados en público, Ilegando así a mucha más gente de la que estaba en condiciones de poder leerlos. Esto es lo que sucedió en Cascante en 1555. Allí Sancho Jiménez, alcalde, sostuvo que una noche estando en su cama oyó que se estaban cantando ciertas coplas, y al día siguiente fueron hallados varios libelos difamatorios contra su persona ${ }^{60}$. En la misma localidad de Cascante la mañana del 23 de diciembre de 1566 se fijaron "ciertos libelos famosos" contra la fama y honra de Pedro Garcés y Sancho Garcés, así como "de otras personas casadas y principales". Según se recoge en la queja criminal que presentaron los injuriados:

57. García de Enterría, M. C., "Lectura y rasgos de un público". Edad de Oro, 12 (1993), pp. 119-130.

58. Galende Díaz, J. C., "Cultura escrita en época cervantina". Cuadernos de investigación histórica, 22 (2005), pp. 173-190.

59. Bouza, F., Palabra e imagen en la Corte. Cultura oral y visual de la nobleza en el Siglo de Oro. Madrid, 2003, p. 28.

60. AGN, Tribunales Reales. Procesos, núm. 144725. 
«Muchos de los acusados o los más de ellos leyeron los dichos libelos y los anduvieron leyendo y mostrando a todos, y en especial el dicho Pedro Ruiz, y sin haberlos quemado ni rasgado, y los demás acusados supieron en hacerlo y tuvieron noticias de ellos» ${ }^{61}$.

La composición de un escrito difamatorio fue, en ocasiones, precedida de la elaboración de toda una serie de cánticos injuriosos que fueron entonados, preferentemente, durante la noche. Estas coplas, cuando fueron redactadas, tuvieron la categoría de libelos porque en ellas se atacaba al honor y fama de determinados individuos, permitiendo a su vez que se conformasen estados de opinión que llegaron a ser en muchos casos omnipotentes. De este modo, también encontramos en otras localidades navarras ejemplos acerca de la divulgación oral del contenido de todo tipo de proclamas. En Corella en 1561 sucedió algo similar a lo que aconteció en Cascante, pues allí se publicaron una serie de coplas a modo de libelo que "han cantado públicamente y a altas voces" ${ }^{62}$ algunos mancebos de la localidad. Algo parecido es lo que ocurrió en Olite en la cencerrada que tuvo lugar en 1570, en donde el hijo de Cristóbal de Irigoyen "leyó el papel y lo que en él contenía públicamente pregonándolo a voces"63. Al igual que lo acontecido en los casos anteriores, en la localidad de Peralta aparecieron una serie de libelos en 1614 contra la Marquesa de Falces que "se han cantado públicamente" ${ }^{\prime \prime 4}$.

¿Puede hablarse de esta manera de la configuración de distintas esferas de opinión? Según Burke y Briggs ${ }^{65}$ éstas se caracterizaron por su enorme variedad y complejidad, pero si llamaron la atención por algo fue porque crearon espacios propios. Sin duda alguna -como sostuvo Chartier ${ }^{66}$-, la enorme fuerza y capacidad sugestiva que caracterizó tanto a la escritura como a la lectura permitieron transformar por completo lo que sus receptores pensasen sobre un asunto concreto. Libelos y pasquines fueron propensos a provocar todo tipo de reacciones. Sin embargo, lo más destacado fue la enorme potencialidad persuasiva que los caracterizó. De este modo, a lo largo de los siglos modernos la calle se convirtió en el espacio predilecto en donde se dieron a conocer todo tipo de informaciones, dentro de las cuales se encontraron las proclamas de carácter difamatorio.

61. AGN, Tribunales Reales. Procesos, núm. 97540, fol. 223.

62. AGN, Tribunales Reales. Procesos, núm. 145456, fol. 1.

63. AGN, Tribunales Reales. Procesos, núm. 38206, fol. 96.

64. AGN, Tribunales Reales. Procesos, núm. 14117, fol. 2.

65. Burke, P.; Briggs, A., De Gutenberg a Internet. Una Historia Social de los medios de comunicación. Madrid, 2002, p. 88.

66. Chartier, R., Espacio público, crítica y desacralización en el siglo XVIII. Los orígenes culturales de la Revolución francesa. Barcelona, 1995, p. 82. 
Si bien también debo señalar que hubo ocasiones en que existieron personas que trataron de gestionar y dirigir la opinión pública local en una u otra dirección. Esto es lo que sucedió en Lodosa. En este caso fueron fijados en el mes de diciembre de 1804 dos pasquines contra Pedro Antonio Rodríguez. Los autores de sendas proclamas nunca fueron descubiertos, aunque hubo testigos que apuntaron a que su autor pudo ser el vicario de la parroquia, Romualdo de Aragón. Lo que sí que fue cierto es cómo este personaje incitó en múltiples ocasiones a varias vecinas a que leyesen lo que contenían aquellos pasquines. Así sucedió en el caso que relata María Santos Mendijur, quien afirmó:

«En la mañana de dicho día 20 de diciembre, hallándose en el atrio o cementerio de la misma iglesia, Don Romualdo de Aragón, presbítero sacristán de la misma parroquia a la sazón que dicha testigo se dirigía a la iglesia a oír misa le dijo a ésta, por dicho Don Romualdo, se acercase a donde se hallaba fijado dicho pasquín y lo leyese, y que la propia diligencia hizo con otras varias mujeres que entraban y salían de la iglesia ${ }^{67}$.

En definitiva, de una manera o de otra se trató de lograr la máxima eficacia en la transmisión de conceptos que pretendieron servir para movilizar al mayor número posible de personas. Su intento por lograr modelar a esas esferas de opinión a las que me estoy refiriendo no resultó factible sin recurrir de forma generalizada a cuestiones que eran más susceptibles de generar una respuesta positiva entre sus receptores. De esta manera, se escogieron temáticas a tenor de su posible aceptación sobre el público al que fueron dirigidas. Este tipo de manifestaciones literarias tuvieron una clara finalidad de origen, como fue actuar sobre la opinión pública, porque para ello fueron expuestos en lugares en donde pudieron ser leídos y oídos por un número destacado de personas. ¿Por qué sino fueron fijados o repartidos en espacios de gran afluencia de público? La pretensión de articular un estado de opinión se hace explícita, no sólo con la visibilidad de los textos, sino también con su accesibilidad, pues éstos se caracterizaron por el empleo de un vocabulario y un léxico apropiado para tal finalidad, junto al uso de una caligrafía basada en letras grandes que permitieron descifrar de un modo más inteligible lo que en ellos se contenía.

Resulta factible, por tanto, sostener la existencia de esferas de opinión a través de las cuales circularon chismes y rumores. Éstas fueron alimentadas por el continuo caudal de proclamas sediciosas que aparecieron en forma de libelos y pasquines. Su simple presencia contribuyó, como ya he indicado, a la conformación de un sentir favorable, en muchas ocasiones, a lo que en ellos se decía. De no ser por su enorme capacidad persuasiva, ¿por qué Sebastián de Oteiza pretendió que todo el mundo leyese un libelo que apareció fijado en la

67. AGN, Tribunales Reales. Procesos, núm. 94250, fol. 5. 
Plaza del Castillo de Pamplona? En 1636 este personaje se encontró un escrito difamatorio que:

«Leyó, y pudiendo quitarlo de allí o rasgarlo, no sólo no lo hizo, pero dijo a todos los que allí se hallaron que mirasen aquel papel con lo cual fueron a leerlo y leyeron otros cuatro de los que allí estaban, con que el dicho libelo se publicó y divulgó entre todos ${ }^{68}$.

Sebastián de Oteiza fue consciente de lo que podía conseguir si lograba difundir el contenido de ese libelo, no ya sólo por los habitantes de Pamplona, por ello "no contento con esto, siendo causa de que se publicase y divulgase más fuera de esta ciudad, escribió todo lo referido y lo que el dicho libelo contenía a su padre" ${ }^{\prime 69}$. En Estella son varios los testigos que afirmaron haber leído la información que le mandó a su padre, y en donde se contenían dichos papeles. ¿Por qué intentó publicar el contenido de dicho libelo en otras localidades del reino, sino para tratar de influir en un mayor número de posibles receptores?

Por tanto, puedo concluir que este tipo de prácticas se convirtieron en instrumentos idóneos para despertar la murmuración, provocando a su vez el descontento popular. A su vez, gracias a ellos se lograron encauzar de alguna manera los vaivenes de la opinión pública. Esta última era de vital importancia y muestra de ello fueron las continuas disposiciones y bandos que se promulgaron contra libelos y pasquines debido a la profunda preocupación de las autoridades por lograr evitar su enorme capacidad persuasiva. La proliferación de este tipo de medidas, encaminadas todas ellas a poner fin a la aparición de escritos y de cánticos sediciosos nos evidencia la fuerza que éstos tuvieron sobre la opinión y el subconsciente de estas comunidades. De no ser por su fuerza y virulencia no se hubieran tomado tantas molestias. Mantener el orden y evitar que influyesen de un modo u otro en el pueblo fue un motivo de preocupación latente durante toda la Edad Moderna.

\section{Control y represión}

Durante los siglos modernos la formación de los estados provocó la aparición de las primeras fuerzas creadas con el único objeto de mantener el orden público. De este modo comenzó el proceso por el cual las autoridades trataron de monopolizar el uso de la violencia, asumiendo para ello la responsabilidad de proteger a sus ciudadanos. Además de los decretos normativos que se promulgaron y de las sentencias que se dictaron, cabe destacar otro tipo de medidas preventivas que fueron tomadas por las más altas instancias para controlar los grupos, los lugares y los períodos especialmente conflictivos. Uno de los

68. AGN, Tribunales Reales. Procesos, núm. 102342, fol. 44.

69. AGN, Tribunales Reales. Procesos, núm. 102342, fol. 44. 
momentos más proclives a la alteración del orden público fue la noche, por ello las autoridades para tratar de lograr cierta estabilidad y prevenir así la criminalidad decidieron aumentar la vigilancia. El mantenimiento de la seguridad pública fue una de las principales atribuciones locales.

Como se ha comprobado la caída del sol no significó un receso de la actividad delictiva, más bien al contrario, pues siguió vigente e incluso surgieron sucesos específicos, como las bandas de jóvenes que salían a dar serenatas o cencerradas, así como portar armas, lo cuál provocó todo tipo de pendencias y altercados. La noche durante los siglos modernos fue sinónimo de inseguridad. Para poner fin a estos comportamientos una de las principales manifestaciones de la actividad policial fueron las rondas nocturnas. En éstas el papel de los alcaldes ordinarios en cada localidad fue primordial, puesto que estaban encargados de velar por la seguridad ciudadana, debiendo salir a rondar por los lugares más convenientes y pudiendo ser acompañados si fuera necesario por los alguaciles y gentes del lugar. Sin duda alguna, la colaboración de los vecinos resultó primordial en algunas ocasiones para la persecución de la delincuencia. En Sangüesa, por ejemplo, se puede apreciar como la participación de algunos habitantes en estas rondas nocturnas fue algo frecuente. De esta manera, una noche del mes de junio de 1589, tal y como afirma Jerónimo de Pueyo, "salió a rondar en compañía de Juan de Mendigacha, teniente de almirante, y Pedro de Ansó, sastre, como lo tiene de costumbre el salir con el dicho almirante" ${ }^{\prime 70}$. Un caso más de la colaboración vecinal en la persecución de posibles delitos durante las noches nos lo encontramos en la villa de Cáseda en 1661. En este caso, Pedro Uscarres señala que "iba una noche con el alcalde" cuando oyeron que Pedro de Güesa y Juan Vicente andaban tocando unas guitarras, lo que provocó que "acudió este testigo con el alcalde por ir en su compañía", aunque "se fueron apartando a los acusados con que no les pudieron dar alcance ${ }^{\prime \prime 71}$. Tampoco debe sorprendernos que en Tafalla el 24 de septiembre de 1754 Miguel de Barasoain señale que "por orden de dicho alcalde buscó algunos vecinos para rondar y pesquisar a algunos de la música". Según relata "esperaron a que diesen las doce de la noche y que habiendo salido de ronda dicho alcalde, su teniente, dos ministros y otros, hasta el número de nueve o diez personas se esparcieron según se convenía y a luego que oyeron la música salieron los de la ronda de una y otra parte y se escaparon los de la música"72.

Pese a ello, lo cierto es que en la mayoría de los casos la conformación de las rondas nocturnas que efectuaron las autoridades locales obedeció a una detallada planificación, puesto que por regla general sus acompañantes solían ser siempre los mismos. Así, por ejemplo, en Estella se nos informa de que el 3

70. ADP, Audiencia Episcopal. Procesos, C/ 124 - no 4, fol. 5.

71. ADP, Audiencia Episcopal. Procesos, núm. C/ 629 - no 27, fol. 3.

72. ADP, Audiencia Episcopal. Procesos, núm. C/ 1643 - nº 5, fol. 4. 
de marzo de 1778 "anduvieron de ronda acompañando al alguacil y de otras personas a su confianza por las calles de esta ciudad deseosos de evitar cualquier género de desórdenes que se pudiesen experimentar"73. Lo cual también puede apreciarse en Puente la Reina, pues allí la noche del 6 noviembre de 1805 se experimentó en la villa "el exceso y desorden de relinchos, algarada, gritería y alborotos, en tanto grado que muchos de sus vecinos se quejaron de semejantes insultos y atentados", fruto de lo cuál Beremundo de Eraso, justicia, "salió en compañía del señor alcalde y de Agustín de Irurzun y Jerónimo Undiano, sus compañeros de ronda", y pese a que se "recorrieron todo el pueblo no encontraron a los sujetos autores de los excesos" ${ }^{\prime \prime 4}$. Sin embargo, en otras ocasiones la conformación de estas cuadrillas obedeció a parámetros mucho más espontáneos. De este modo, en Esparza en 1567 podemos apreciar, según Bartolomé García, como fue junto a "otros sus compañeros con el alguacil Orbara por mandato de Don Jerónimo de González a rondar por la ciudad"75.

Lo que no puede ponerse en duda es la importancia que tuvieron las rondas como mecanismos de control y represión que pusieron en marcha las autoridades para tratar de evitar los desórdenes públicos que se producían en cada comunidad vecinal. Del destacado papel que jugaron éstas nos hablan algunos ejemplos encontrados en el reino de Navarra. Sin duda, en ocasiones fue el propio Fiscal quien señalaba el verdadero cometido de las rondas como instrumentos de control socio-comunitario, así en unos sucesos que tuvieron lugar en Falces en 1566 tras efectuar una ronda Juan de Mirafuentes, baile, en donde resultó herido como consecuencia de ello, y pese a que no tenía autoridad para efectuarla se recoge en su favor en el proceso que "decimos que estando por ley de este reino hecha por Vuestra Majestad y uso y costumbre de siempre en acá de hacer ronda de noche la justas en especial en la dicha villa habiendo necesidad de hacerla cada noche por no dar lugar a muchos delitos ${ }^{\prime \prime 76}$. Tan esenciales llegaron a ser las rondas nocturnas para evitar todo tipo de escándalos que en 1585 se presentó en Peralta una queja criminal por parte del Marqués de Falces para que sus oficiales pudiesen ir a rondar, en la que se decía lo siguiente:

«Estando mandado que los regidores de la villa no lo hagan ni impidan a los oficiales del dicho Marqués que tiene en la dicha villa hacen dos cosas, la una que no rondan y la otra que no dejan rondar y por ello en esta villa han sucedido y suceden inconvenientes, riñas, muertes, robos y como no está la villa cerrada ni cercada y con facilidad se pueden esconder los delincuentes en los campos hay necesidad que con más vigilancia y cuidado se haga la ronda y para ello conviene que se taña a los que no

73. AGN, Tribunales Reales. Procesos, núm. 34147, fol. 1.

74. AGN, Tribunales Reales. Procesos, núm. 194304, fol. 2.

75. AGN, Tribunales Reales. Procesos, núm. 198577, fol. 2.

76. AGN, Tribunales Reales. Procesos, núm. 145881, fol. 23. 
quieren permitir alcalde y jurados, suplica a Vuestra Majestad librar una provisión mandando por ella que todas las noches toque una campana a la queda como se usa en otras partes de este reino y que el dicho baile por sí o su teniente haga la ronda, y los jurados no se lo impidan pues toca a la jurisdicción hacerla y no la tienen los jurados» ${ }^{77}$.

Una muestra más de la elemental función que desempeñaron estas prácticas represoras fue que cuando no consiguieron controlar o erradicar los comportamientos que ahora trataré de analizar no podía existir una convivencia pacífica entre los vecinos de cada comunidad. Por ello, cuando un encargado de mantener la estabilidad nocturna dejaba sus labores a un lado era duramente castigado. Pedro de Orbaiz, teniente de almirante, fue acusado de ello en 1596 cuando Guillén de Grez, Salvador Zurita, Juan de Ansó, Juan Remírez y otros vecinos de Sangüesa anduvieron de noche "voceando y gritando" mudando sus voces "difamando a gentes honradas y a mujeres casadas", todo lo cual se agravaba porque el dicho Pedro de Orbaiz "era y es obligado de hacer cada noche ronda y limpiar las calles de semejantes ocasiones y evitar aquéllos" ${ }^{\prime \prime 8}$.

¿Que altercados fueron habitualmente los más perseguidos a través de las rondas nocturnas? En primer lugar creo conveniente reseñar el cuidado que tuvieron las autoridades para tratar de reprimir los excesos que se produjeron durante las jornadas carnavalescas, por lo que la eficacia de las rondas era de suma importancia en aquellas jornadas. Por ello, en la localidad de Allo en 1591 el jurado local Ugalde nos informa en un proceso judicial que "por evitar los ruidos y enojos y escándalos que semejantes días y noches como es carnestolendas se acostumbran hacer en la dicha villa"79 salió a mantener la quietud y el sosiego del vecindario. Algo similar ocurrió en Viana el 11 de febrero de 1698, en donde salió un grupo conformado por Ignacio Martínez, alcalde, quien "andaba de ronda con Martín de Zugarrondo, Merino de esta ciudad, y en su compañía Antonio de Lara y otras personas por las calles de esta ciudad aquietando los excesos y reconociendo la gente para la quietud de la ciudad por ser después de la hora de queda"80. Por último, el protagonismo que detentaron las rondas durante las noches de Carnaval para conseguir controlar las alteraciones del orden público que se producían también nos lo corrobora para el caso de Fustiñana en 1784 Matías de Salvatierra ${ }^{81}$. Por otro lado, en segundo lugar, de la importancia de las rondas nocturnas para frenar la celebración de cencerradas nos informa Francisco Cuartango, regidor, quien colaboró en una de ellas para evitar que se diese una matraca en Peralta en 1653 cuando "salió de ronda el

77. AGN, Tribunales Reales. Procesos, núm. 88344, fol. 1.

78. AGN, Tribunales Reales. Procesos, núm. 99628, fol. 8.

79. AGN, Tribunales Reales. Procesos, núm. 148490, fol. 1.

80. AGN, Tribunales Reales. Procesos, núm. 125297, fol. 1.

81. AGN, Tribunales Reales. Procesos, núm. 156193. 
alcalde ordinario en compañía de este testigo y de Juan Moreno, Miguel Romeo, regidores, Pedro de Ibero y Juan de Güete". Sobre ellas nos expone que "esta costumbre que ha habido y hay en semejantes días y noches para suceder alborotos e inquietudes que pueden suceder y suceden" ${ }^{\prime \prime 2}$. Sin embargo, en tercer lugar, no menos frecuentes fueron los excesos que cometieron constantemente las cuadrillas de jóvenes durante sus aventuras nocturnas. El principal método para atajar los excesos que durante aquéllas se solían cometer fueron las rondas nocturnas encabezadas por las autoridades de cada localidad, aunque estos mecanismos no siempre resultaron eficaces. Así, por ejemplo, en la localidad de Cascante su alcalde, Pedro de Gaona y Munárriz, nos informa en 1770 de que "hay cuadrilla de mal vivir, que salen cargados de armas a deshoras de la noche, perturbando el pueblo con músicas y mofas contra la justicia y cometiendo raterías y hurtos escalando para ello casas", sin embargo, para atajarlos "habiendo dispuesto varias rondas así de su merced personalmente como de su teniente, el presente día (4 de diciembre) le ha dado noticia dicho teniente que andando de ronda la noche pasada había encontrado diferentes gentes que le hicieron carracas y aunque procuró sus prisiones se le hicieron a excepción de que habiendo seguido tres hombres con la voz del rey que iban con armas se refugió acosado del seguimiento de un forastero vecino de Tudela" ${ }^{\prime \prime 3}$.

No debe sorprendernos, por tanto, que en otras ocasiones las autoridades decidiesen emprender ciertas novedades para tratar de apaciguar los excesos que se cometían durante las noches en muchas localidades del reino de Navarra. De este modo, podemos destacar el caso que tuvo lugar en la ciudad de Cascante en 1800, en donde su alcalde Francisco Paula Marco, debido a que "no puede cumplir con muchas de sus obligaciones de su ministerio como son las de rondar por las noches y otras de esta naturaleza" como consecuencia de haberle nombrado la localidad diputado en las Cortes Generales de Navarra le fue preciso marcharse veintiún días. Cuando regresó indicaba que "encontró a este pueblo muy alborotado en continuas rondallas de mozos, tanto con músicas como sin ellas, apedreando las más noches las ventanas y balcones, cantando y diciendo mil indecencias, llegando a tanto la barbaridad como a poner modo de mofa algunas noches calaveras y huesos humanos en los balcones". Desde su punto de vista "es intención de remediarlo aunque fuese a costa de los mayores desvelos". Los mecanismos que este personaje puso en marchar fueron algo más allá de una simple ronda nocturna, puesto que la víspera de San Pedro, "suponiendo y teniendo noticia que aquella noche había de haber música y que para enramar los balcones de las mozas habían de causar destrozos considerables en los huertos y árboles fructíferos como los acostumbran" señalaba:

82. ADP, Audiencia Episcopal. Procesos, núm. C/ 1017- no 24, fol. 5.

83. AGN, Tribunales Reales. Procesos, núm. 127765, fol. 1. 
«Medité en hallar algún medio que con suavidad precaviese estos malos y ciertamente no me ocurrió otro que el de la fuerza y violencia saliendo a noche con gente armada y ver si podía apresar los hombres. Efectivamente me era sensible apelar a este último medio de que podían resultar tan perjudiciales consecuencias, pero no hallaba otro en aquellas circunstancias casi lo adopté entre mí mismo y tal vez lo hubiese practicado pero yendo aquella noche a casa de Francisco Jiménez donde tiene orquesta los días de fiesta y donde se hallaba también el regidor Ángel Romano comuniqué con ellos mi pensamiento y discurrimos otro medio más suave y acostumbrado, pienso que no sólo en este pueblo sino en muchos de este Reino y fue suplicar a los músicos nos acompañasen con los instrumentos a dar una vuelta al pueblo y recoger a los mozos que hubiese por las calles a que viniesen con nosotros y después retirarlos a sus casas» ${ }^{84}$.

Sin embargo, pese a su plan, como indica el regidor local Pascual Rodríguez de Arellano, "habiendo andado poco rato por el pueblo tañendo y recogiendo algunos mozos que se hallaban oyó muy cerca una música y llegándose a ella vio al hijo mayor del teniente con una guitarra", acto seguido "Ilegaron los mozos con la mayor precipitación y arrojo y les empezaron a tirar muchas pedradas con unas voces muy descompuestas e indecentes amenazándoles y diciendo tírales, mátalos, caiga el que caiga, y otras expresiones y palabras obscenas" ${ }^{\prime \prime 5}$. Situación esta última que fue bastante habitual, puesto que no resultó nada extraño que durante las rondas efectuadas por las autoridades locales se produjesen altercados violentos contra quienes iban en ellas, e incluso en ocasiones agresiones que causaron fallecimientos. Por ejemplo, en Tafalla en 1733 se aprecia el escaso respeto que los que participaban en aquellas correrías nocturnas tenían hacia las autoridades que salían de ronda, puesto que como expone Pedro Díez de Ulzurrun, sustituto fiscal, yendo junto a sus compañeros en busca de José de Aguirre y Francisco de Abinzano ante la petición de ayuda al rey el dicho Aguirre le replicó "que rey ni que cuerno" ${ }^{86}$. Por último, la noche del 7 de mayo de 1800 en la localidad de Falces estando el alcalde de ronda algunos sujetos le hicieron "burlas, silbándole, chiflando y relinchando", quienes "tuvieron la osadía de dispararle varias piedras llegándole a pegar una de ellas en la cabeza y brazo izquierdo" y lo más destacado es que todos estos hechos "se cometieron no obstante de antes le elevó e imploró la respetable voz de su majestad"87.

Para finalizar, en cuarto lugar, en el caso de la proliferación de proclamas difamatorias -caso de libelos, pasquines, coplas o cartas anónimas- el objetivo de las autoridades no fue otro que intentar conseguir regular el flujo de estos escritos. Su

84. AGN, Tribunales Reales. Procesos, núm. 194036, fol. 6.

85. AGN, Tribunales Reales. Procesos, núm. 194036, fol. 8.

86. AGN, Tribunales Reales. Procesos, núm. 126570, fol. 14.

87. AGN, Tribunales Reales. Procesos, núm. 171544, fol. 1. 
carácter infamante determinó su persecución, la cual quedó plasmada en bandos y edictos promulgados por las autoridades civiles que prohibieron su difusión e incluso su conservación. Debido a esto último es por lo que en multitud de ocasiones no se han conservado los escritos originales, pues a la prisa que tuvieron por colocarlos le sucedió la rapidez por arrancarlos u ocultarlos. Pese a ello, el objetivo último fue intentar descubrir a sus respectivos autores para castigarlos. Por otro lado, su principal finalidad fue lograr frenar la aparición de este tipo de manifestaciones porque resultaban perjudiciales para el mantenimiento del orden público. Por tanto, los mecanismos que se pusieron en marcha durante los siglos modernos para lograr la consecución de esta ambiciosa meta fueron variadísimos. Sin embargo, de todos ellos el más significativo fue la práctica continuada de aumentar el control y la censura. A través de ellas las autoridades civiles creyeron factible poner fin a su desenfrenada actividad crítica.

Si bien la puesta en marcha de una estricta censura se mostró como una de las actitudes más relevantes de las que se adoptaron, lo cierto es que su eficacia en algunas circunstancias resulta a todas luces dudosa. Como muestra de su escaso éxito tendríamos el hecho de que dichas proclamas difamatorias siguieron apareciendo de forma periódica. De esta manera se aprecia el relativo éxito que tuvieron los complejos métodos de censura y control puestos en marcha. Sin duda, los principales afectados de la cruzada que se emprendió contra esta literatura subversiva fueron los documentos impresos. Sin embargo, los tentáculos de los que se valió la censura -como expone Cátedra ${ }^{88}$ - no lograron alcanzar a este tipo de manifestaciones cuando estuvieron escritas a mano. Con esto tampoco quiero decir que sus autores se libraran del acoso que sufrieron algunos por publicar escritos tan perniciosos, lo que provocó que estas manifestaciones literarias surgiesen en su mayoría de un modo anónimo, aunque en algunas de ellas emplearon pseudónimos con el objetivo de encubrir tanto la personalidad de sus autores como sus protestas.

Por tanto, ¿cómo descubrir a sus autores? Uno de los métodos más efectivos fueron las rondas nocturnas. En éstas, como ya he apuntado, se recurrió a nombrar a determinados personajes para que se encargasen de dar con sus autores. En el caso navarro podemos destacar el suceso que tuvo lugar en Estella en 1658, en donde aparecieron "unos papelones, unos versos o coplones" que Pedro de Echarri, teniente de justicia, "quitó en primera instancia" 89 mientras iba de ronda por la ciudad. Bien es cierto que tampoco resulta extraño que fuese cualquier vecino quien encontrándose con algún libelo o pasquín decidiese arrancarlo para evitar que otras personas tuviesen conocimiento de su contenido. De este modo, Pedro Chocarro se encontró en 1655 en la localidad de

88. Cátedra, P., Invención, difusión y recepción de la literatura popular impresa (siglo XVI). Mérida, 2002, p. 82.

89. AGN, Tribunales Reales. Procesos, núm. 59289, fol. 16. 
Miranda de Arga con un libelo y "habiéndolo comenzado a leer vio que hablaba contra Don Ambrosio de Carranza y después de haber leído el último dicho segundo renglón no quiso leerlo porque las palabras eran tan feas ${ }^{\prime \prime 0}$ y se dispuso a quitar el escrito de donde se hallaba fijado. Igual sucedió en Estella la mañana del 21 de julio de 1711 cuando Gregorio de Ayala, cocinero, "salió del convento" a leer un papel que se había fijado allí contra José de Olano y "lo quitón ${ }^{\prime \prime 1}$ por las graves injurias que éste contenía.

\section{El recurso a los pleitos judiciales}

En la lucha contra el desorden público también resultó sumamente eficaz la actividad judicial que llevaron a cabo las autoridades civiles. Como veremos a continuación, el objetivo primordial de éstas fue lograr pacificar la sociedad navarra durante los siglos modernos. No cabe duda que las fuentes documentales nos muestran la enorme cantidad de procesos judiciales que se originaron fruto de la perturbación del orden público en las sociedades europeas de la Edad Moderna. En éstos aparece la violencia como una realidad cotidiana, pudiéndose afirmar que se trató de una constante en las relaciones sociales. Sin duda, como señala Dinges ${ }^{92}$, lo importante es analizar cómo la justicia trató de controlar este tipo de comportamientos socio-comunitarios, para lo cual es inevitable estudiar qué tipo de instrumentos emplearon. Es por ello por lo que a continuación voy a centrarme en los pleitos como mecanismos de control y de represión. Desde mi punto de vista, concibo la actividad procesal como una herramienta más de control que fue empleada por las autoridades para tratar de frenar cualquier actitud que supiese la alteración del orden público.

En toda causa criminal las declaraciones de los testigos presentados por las dos partes protagonistas fueron uno de los elementos primordiales para obtener información relativa a los delitos que se juzgaban. Sin embargo, el método más Ilamativo de todo proceso penal durante los siglos modernos fue el empleo del tormento. La tortura se afianzó y conservó una función relevante porque así lo exigió el sistema represivo imperante en la administración de justicia. Pese a ser considerada como una pieza ineludible por su naturaleza intimidativa, ya en la segunda mitad del siglo XVIII se halló en plena fase de desprestigio, aunque ya antes algunos tratadistas, intelectuales y juristas habían escrito en contra de aquella forma de proceder para obtener la confesión de los reos. Así en plena Ilustración Cesare Beccaria en su capítulo decimosexto -De la tortura- se pre-

90. ADP, Audiencia Episcopal. Procesos, núm. C/ 1042 - no 23, fol. 83.

91. AGN, Tribunales Reales. Procesos, núm. 60527, fol. 17.

92. Dinges, M., "El uso de la violencia como forma de control social en la Edad Moderna", Fortea; Gelabert; Mantecón. Furor et rabies. Violencia, conflicto y marginación en la Edad Moderna. Santander 2002, pp. 65-67. 
guntó por el fin político de este castigo, a lo que éste señaló que su objetivo era el terror de los demás hombres, obligando a los reos a confesar sus delitos ${ }^{93}$.

El género humano de manera espontánea no tiende hacia la autoconfesión de la culpa, por ello en ocasiones hubo que emplear distintos mecanismos encaminados a lograr confesiones de culpabilidad. Entre aquéllos nos encontramos la aplicación del tormento. Este tipo de situaciones podían ser demandadas no sólo por el juez, sino también por la parte acusadora, aunque su disponibilidad final fue asunto exclusivo de los magistrados, pese a que también es cierto que antes de someter a alguien a un proceso de esta naturaleza se debían escuchar a las partes litigantes. Sin embargo, una vez aprobado se incomunicaba al reo para evitar que le proporcionasen drogas o pócimas que sirviesen para reducir su sensibilidad. El lance del tormento revelaba el temple del acusado y superarlo sin confesar era ya mérito suficiente para ingresar en el grupo de los hombres honrados, mientras que ceder al dolor y testificar contra sí mismos podía suponer perder el aprecio de la comunidad. Pedro Alzorriz, vecino de Sangüesa, en la causa criminal que tuvo abierta entre 1666 y 1668 por varias agresiones en las que participó fue condenado "a que sea puesto a cuestión de tormento y se le dé aquel reiteradas veces al arbitrio de los jueces de la sala" ${ }^{\prime 94}$, aunque finalmente no llegó a producirse dicho tormento.

En un pleito acaecido en Falces hacia 1582 sobre la elaboración de ciertos libelos difamatorios fue solicitado por parte del procurador de los demandantes que María de Marzán "sea puesta a cuestión de tormento y preguntada de los demás partícipes en este delito" ${ }^{\prime 95}$. Un caso similar tuvo lugar en la villa de Torralba del Río en 1578, en donde no se lograba dar con los autores de "ciertos cartapeles y cédulas" en donde se recogían "palabras muy atroces e injuriosas y afrentosas" contra Domingo de Aguirre. Llegados a este punto, uno de los acusados, Nicolás López, fue condenado "a que sea puesto a cuestión de tormento". Dicho personaje fue trasladado a la cámara del tormento de Pamplona y allí los alcaldes le dijeron:

«Está condenado a que se le de tormento y que le advierten y requieren de partes de su majestad y suya diga y declare la verdad quien puso los libelos infamatorios contra Domingo de Aguirre y su mujer, y en caso que no lo quisiere decir se le dará el dicho tormento y si en el recibiere alguna lision y daño o muriere será a su cargo y no de los dichos señores alcaldes».

Una vez advertido empezó el interrogatorio, y visto que no declaraba nada nuevo mandaron a Esteban Martínez, ejecutor de la Real Justicia, "lo ponga en

93. Beccaria, C., De los delitos y las penas. Ventura. Barcelona, 1983, p. 80.

94. AGN, Tribunales Reales. Procesos, núm. 17004, fol. 626.

95. AGN, Tribunales Reales. Procesos, núm. 28680, fol. 31. 
el potro y escalera del tormento". A continuación, procedió a desnudar al acusado y lo puso "en el dicho potro y escalera y le puso los cordeles y garrotes". Después de haberlo atado, antes de apretarle los garrotes, le volvieron a exhortar que dijese la verdad "porque si muriere o se le quebrare pierna o brazo será a su cargo", ante lo cual "sus señorías mandaron apretar los garrotes de las espinillas y apretando principio a llorar y dar voces" ${ }^{\prime \prime 6}$. Pese a todo el sufrimiento que le hicieron padecer a Nicolás López no lograron obtener nada que no hubiese dicho con anterioridad. Es cierto que se trató de una práctica bastante extendida, pero su eficacia resultó prácticamente nula. A pesar de los castigos corporales a los que sometieron a los testigos y del sufrimiento al que fueron expuestos no lograron, en general, nuevas declaraciones por parte de los condenados, aunque en ocasiones el dolor resultase insoportable e inaguantable. Aunque también es cierto -como expuso Tomás y Valiente ${ }^{97}$ - que este método sirvió para obtener ciertas confesiones, pese a que éstas no fueron del todo veraces, todo lo cual se sustentó en el efecto tanto inquisitivo como intimidativo que causó sobre sus reos.

En otro de los casos relativos a la colocación de libelos Pedro de Sarasa fue condenado a recibir tormento durante su desarrollo. En este caso podemos apreciar de nuevo cómo el testigo pese al insoportable dolor al que hizo frente no modificó ni un ápice su declaración. Así en el proceso en cuestión se recoge lo siguiente:

"Visto los dichos señores alcaldes que el dicho Pedro de Sarasa estaba firme en lo susodicho mandaron al dicho ejecutor diese media vuelta a los dichos garrotes se bajo de las dichas protestaciones y habiendo comenzado a darla y prosiguiendo en esto dijo el dicho Pedro de Sarasa que no sabe ni puede decir con verdad más de lo que tiene dicho y comenzó a exclamar y dar voces pidiendo y suplicando a la Virgen del Camino y al bienaventurado San Cernin fuesen medios con nuestro señor para que lo sacase del trabajo en que estaba, después de haber dado la dicha media vuelta a los dichos garrotes los dichos señores alcaldes le comenzaron a exhortar y decir que dijese la verdad y descargare su conciencia en razón de lo susodicho porque no lo haciendo se proseguiría en darle el dicho tormento y si por caso muriere en él y le quebrase algún brazo o pierna o recibiere alguna otra lesión en su persona será a su cuenta y cargo y no al de los dichos señores alcaldes porque estaba firme en decir que ya la tenía dicha y no podía decir otra cosa con verdad o pena de ir al infierno debajo de las dichas protestaciones. Los dichos señores alcaldes mandaron al dicho ejecutor que diese una vuelta a los dichos garrotes y en el discurso que la daba comenzó a invocar los nombres de la Virgen de Monsarrate y Virgen del Camino y glorioso

96. AGN, Tribunales Reales. Procesos, núm. 11411, fol. 200.

97. Tomás y Valiente, F., La tortura judicial en España. Barcelona, 2000, p. 209. 
San Cernin pidiéndoles y suplicándoles fuesen medios para que nuestro señor los sacase del trabajo en que estaba y los dichos señores le volvieron a exhortar y amonestar que dijese la verdad $»^{98}$.

La pregunta que cabría hacerse es si esta práctica sirvió para saber la verdad, bueno, ¿qué verdad? Lo que se pretendía era que el reo dijese que había sido culpable del delito que se le imputaba, así de esta manera todo quedaba ya demostrado. Como se ha podido comprobar la aplicación de la tortura fue uno de los mecanismos más extendidos para la obtención de declaraciones autoinculpatorias durante el transcurso de las causas abiertas con motivo de cualquier acción que perturbase el orden público. En los procesos existentes como consecuencia de la publicación de escritos difamatorios el empleo del tormento se convirtió en una práctica muy socorrida por parte de las autoridades.

Al margen de los castigos físicos que se infringieron en ciertas ocasiones podemos apreciar cómo en algunos pleitos, sin embargo, fueron los propios demandantes o algunos testigos favorables a éstos quienes presentaron escritos para que fuesen cotejados con las proclamas aparecidas con el fin de demostrar quién o quiénes habían sido sus autores. Esto es lo que sucedió en la villa de Sangüesa en 1583. Allí se presentaron unas hojas que "tomó el señor alcalde" en donde se contenía la contabilidad del personaje acusado, Juan de Esclavino, porque "grandeza e iguala y se parece a la del papel del pasquino" ${ }^{\text {"99. }}$. Del mismo modo, expertos en gramática fueron requeridos para que hiciesen rigurosos exámenes del tipo de letra empleada en libelos, pasquines, coplas y cartas anónimas, y compararla así con la de las personas de las que se tenían ciertas sospechas en cuanto a su autoría ${ }^{100}$. Un caso nos lo encontramos en Sangüesa, en donde hallamos las reflexiones de los maestros de primeras letras de la localidad -Juan Asensio de Arrieta y Romualdo de Limorra- con el único fin de acercarse al autor de unos pasquines que se hallaron fijados en cinco casas durante la madrugada del 8 de octubre de 1801. En su declaración afirmaron:

"Que observan en los cinco pasquines, que todas las "oes" que se hallan en medio de dicción están ligadas con las letras siguientes. Igual-

98. AGN, Tribunales Reales. Procesos, núm. 41939, fols. 198-199.

99. AGN, Tribunales Reales. Procesos, núm. 11541, fol. 9.

100. En ciertas ocasiones el interés por la búsqueda del autor o autora de la escritura de libelos, pasquines, sátiras, coplillas o cartas anónimas llevó a jueces a solicitar precisiones y peritajes caligráficos que, sin duda, resultan muy interesantes para la Historia de la Cultura Escrita. Consúltense algunas referencias al respecto en Bouza, F., Corre manuscrito. Una historia cultural del Siglo de Oro. Madrid, 2001, p. 120; Bouza, F., Del escribano a la biblioteca. La civilización en la alta Edad Moderna (siglos XV-XVII). Madrid, 1992, p. 47; Terol i Reig, V., "Escriptures infamants valencianes. A propòsit d'un cartell del segle XVIII", Los muros tienen la palabra. Materiales para una historia de los graffiti. Valencia 1997, p. 156; Orteu Berrocal, M., "La literatura clandestina en la España de Carlos IV". Cuadernos de Historia Moderna, 17 (1996), pp. 71-104. 
mente la letra "s" que sigue a la letra " $\mathrm{e}$ " está ligada, igual que guardan mucha igualdad en la formación y tienen bastante semejanza algunas letras y especialmente la "l", " $\mathrm{t}$ ", " $\mathrm{v}$ ", y de los pasquines con las de las citadas copias de las deposiciones del demandado. Que no se advierte ninguna nota ortográfica en los pasquines, lo cuál sucede también en las copias y en las cartas. Que el "ha" del verbo auxiliar "haber" está en todos los pasquines sin la " $h$ ". Que notan también la particular circunstancia de que todas las "ces" en principio de dicción son mayúsculas, en todos los pasquines excede a algunas letras minúsculas. Que observan también que la mayor de las "enes" de los cinco pasquines eran más abiertas por abajo que por arriba. Que la formación de la " $\mathrm{e}$ " y la "i", vocales, son también muy diferentes en los pasquines de las que se observan en sus copias y las tres cartas. Que el carácter de letra es en parte distinto en los pasquines y guarda relación el doble de alto. Que aunque tienen también otras pequeñas variaciones la letra de los pasquines con las copias y las tres cartas, no son de mérito ni hacen fuerza para variar el juicio de los componentes, quienes de todo lo referido deducen y en conclusión declaran según lo que por las reglas de su facultad entienden que la letra de los pasquines sin que tengan la menor duda en su modo que es de Francisco de Ozcáriz» ${ }^{101}$.

Sin embargo, en la mayoría de los casos la acción de la justicia se vio limitada a identificar a sus posibles autores a partir de las informaciones que se llevaban a cabo en cada proceso. Gracias a éstas se logró analizar las rencillas locales, lo cual permitió identificar a los posibles culpables, pues se suponía que entre ellos estaban los promotores de estos agravios. De este modo, gracias a las causas abiertas se pueden reconstruir los distintos bandos locales e incluso se logran intuir las estrategias concretas que se pusieron en marcha por el control del poder comunitario. Pese a ello, debemos tener en cuenta que las fuentes judiciales tienen sus limitaciones para el estudio de la incidencia de los desórdenes públicos, puesto que su propia naturaleza fue producto de la actividad represora de las instituciones, por lo que deben ser interpretadas dentro de un contexto determinado.

\section{Conclusiones}

Cesare Beccaria ya se cuestionó en el siglo XVIII en su obra titulada De los delitos y las penas qué castigos eran convenientes contra los transgresores del orden público. Así entre los delitos analizados en su capítulo undécimo -De la tranquilidad pública ${ }^{102}$ - se encontraban los que turbaban la tranquilidad pública y la paz de los ciudadanos, como eran los alborotos, resistencias, motines y

101. AGN, Tribunales Reales. Procesos, núm. 193980, fols. 44-45.

102. Beccaria, C., De los delitos..., pp. 71-72. 
tumultos que tenían lugar en las vías públicas. Sin duda, lo que entendemos por violencia colectiva debe ser entendida como una expresión fundamental del género humano a lo largo de los siglos. Pese a ello, lo que nos ha interesado es determinar los motivos que llevaron a confeccionar a las instituciones civiles un ideal de estabilidad y orden público, así como los mecanismos e instrumentos de los que se valieron para alcanzar dichos objetivos.

Es por ello que considero que a través de este estudio se ha logrado constatar la actitud que manifestaron las autoridades civiles en su lucha constante por lograr acabar con la proliferación de desórdenes públicos, dotándose para ello de distintas herramientas. No cabe ningún género de duda que el objetivo primordial que trataron de alcanzar no fue otro que pacificar la sociedad navarra. De esta manera, entre 1512 y 1808 intentaron poner fin a los distintos conflictos que a escala comunitaria perturbaron la estabilidad social y política.

Como ha quedado perfectamente demostrado en este artículo los dispositivos más eficaces que existieron durante estas centurias fueron las rondas nocturnas y los pleitos judiciales. Respecto a las primeras se ha puesto de manifiesto que fue durante la Edad Moderna cuando se crearon las primeras fuerzas destinadas al mantenimiento del orden público. Destacando en ellas el papel tan relevante que desempeñaron los alcaldes ordinarios, resultando éste primordial, ya que ellos se encargaron de velar por la seguridad de sus convecinos, lo que motivó que saliesen acompañados de los alguaciles o de gentes del lugar a rondar por los lugares más problemáticos y propicios para generar disturbios. Sin embargo, ha quedado suficientemente constatado que tampoco debemos menospreciar la importante labor que ejercieron los procesos judiciales que se interpusieron como consecuencia de cualquier perturbación del orden público. Por tanto, considero que a través de este trabajo hemos logrado comprobar que la actividad procesal fue una herramienta más de control y represión que fue empleada por las autoridades civiles para alcanzar sus objetivos de orden comunitario.

En definitiva, sabemos que los desórdenes públicos que se originaron en la Navarra moderna estuvieron unidos no sólo a unas circunstancias espaciales y temporales, puesto que también se vieron perfectamente ensamblados con una serie de motivaciones que originaron dichos altercados. No obstante, lo que se ha puesto de manifiesto gracias a este trabajo es que prevenir los desórdenes públicos y sus funestas consecuencias fue uno de los principales objetivos de las autoridades durante los siglos modernos. Lo cierto es que ya desde el siglo XVI los cuerpos legislativos trataron de controlar y corregir las actitudes lascivas y desviadas que ocasionaban alborotos, riñas y ruidos. Sin embargo, fue durante todo el Antiguo Régimen cuando se produjo una intensificación del control de los comportamientos comunitarios con la única finalidad de mantener el orden público estable y sosegado. 